\title{
Armas y ritual durante la Segunda Edad del Hierro en la mitad Sur de la Galia.
}

\author{
Gadea C. Cabanillas de la Torre
}

\section{Resumen}

A diferencia de los santuarios de la Galia Bélgica, los lugares de culto de la mitad Sur de la Galia no han sido objeto de un estudio global. A partir de una delimitación historiográfica y de la elaboración de un catálogo de yacimientos, el objetivo de este trabajo es reflexionar sobre los criterios de cantidad, calidad y funcionalidad de las armas en contextos rituales, como llave para comprender el transfondo de los rituales de depósito de armamento en los santuarios galos.

PALABRAS CLAVE: Armas; culto; santuarios; pozos; Edad del Hierro; Galia.

\section{Abstract}

On the contrary to the sanctuaries in Belgic Gaul, cult sites located in the southern half of Gaul have never been studied from a global perspective. Based on a historiographical demarcation and a list of sites, the aim of this paper is to discuss the criteria of quantity, quality and function of weapons in ritual contexts as a key to understanding the background of the rituals of weaponry deposition in gaulish sanctuaries.

KEY WORDS: Weapons; cult; sanctuaries; pits; Iron Age; Gaul.

Hasta los años 80, tanto los estudios sobre armamento como sobre religión gala tenían por fuente casi exclusiva los textos antiguos. La arqueología adoleció largo tiempo de dos problemas: uno en cuanto a los objetos, ya que la falta de un corpus suficientemente amplio de armamento galo impedía su estudio específico; y un obstáculo en cuanto a los contextos, puesto que se suponía que los cultos galos se celebraban al aire libre y fuera de cualquier estructura detectable arqueológicamente. No obstante, el descubrimiento en 1977, del santuario de Gournay sur
Aronde (Oise) marcó un hito fundamental en la investigación, ya que por primera vez se excavaba una acumulación extraordinaria de armas en un contexto innegablemente cultual. El estudio de este yacimiento no sólo supuso el inicio de la arqueología del ritual en la Galia prerromana, sino que permitió establecer una tipocronología e impulsó los primeros estudios sobre funcionalidad del armamento galo ${ }^{1}$.

Con el tiempo, la sorpresa suscitada por el hallazgo, la cantidad y la calidad de las publicaciones, así como el descubrimiento, en la misma

\footnotetext{
1 Brunaux y Méniel, 1983 ; Brunaux, Méniel y Poplin, 1985 ; Brunaux, 1987 ; Brunaux, 1996 ; Rapin, 1996
} 
región, de otros yacimientos semejantes han afianzado la percepción de la Galia Bélgica como un epicentro cultual guerrero. La confirmación de la importancia de los ritos de armas en esta zona coincide, además, con la belicosidad particular atribuida a los pueblos belgas por César ${ }^{2}$. De este modo, J. L. Brunaux, responsable de las excavaciones de Gournay y principal especialista en la materia, sostiene incluso que la Galia Bélgica puede considerarse como una región representativa de la actividad cultual de la Galia en la Segunda Edad del Hierro ${ }^{3}$. Efectivamente, en su trabajo sobre las religiones galas (plural significativo que alude a la diversidad de la evidencia de actividades cultuales en tan vasto ámbito cronocultural), los yacimientos mencionados ${ }^{4}$ se localizan casi exclusivamente en la esquina nororiental del actual territorio francés (fig. 1), incluyendo fundamentalmente los departamentos del Oise, Somme y Aisne ${ }^{5}$, y cubriendo, en realidad, menos de la mitad de la Galia Bélgica. Este territorio formaría una unidad cultural en materia religiosa, en la medida en que concentra más de una decena de lugares de culto guerrero, fechados en torno a los siglos IVII a. C, considerados paradigmáticos. Caracterizados por sus espectaculares acumulaciones de armas mutiladas y depósitos faunísticos en recintos delimitados por fosos, se asocian a otras instalaciones cultuales como fosas, altares pétreos y edificios sobre postes de madera. Dicha abundancia de información parece justificar que su estudio de las religiones galas se ciña necesariamente a la Galia Bélgica ${ }^{6}$.

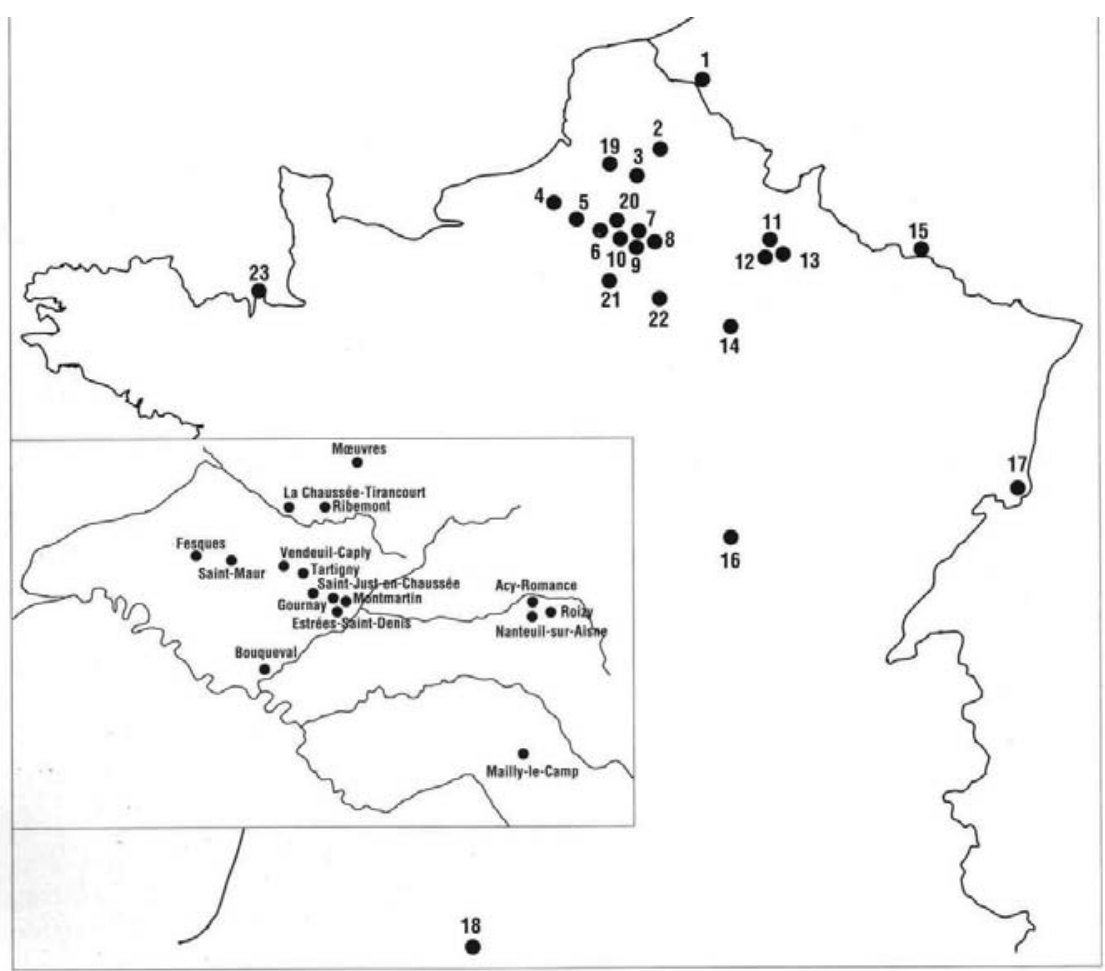

1: Pommeroeul - 2 : Mœuvres - 3 : Ribemont-sur-Ancre - $4:$ Fesques - 5 : Saint-Maur - 6 : Vendeuil-Caply - 7 : Gournay-sur-Aronde - 8: Montmartin - 9: Estrées-Saint-Denis - 10: Saint-Just-en-Chaussée - 11: Acy-Romance - 12: Nanteuil-sur-Aisne - 13 : Roizy-sur-Aisne - 14 : Mailly-le-Camp - 15: Titelberg - 16: Mont-Beuvray - 17 : Saint-Louis - 18: Toulouse - 19: La Chaussée-Tirancourt - 20 : Tartigny - 21 : Bouqueval - 22 : Meaux " La Bauve $n-23$ : Saint-Malo.

Figura 1. Mapa de los yacimientos mencionados en Brunaux, 1996 : 16.

2 En el célebre pasaje de Commentarii de bello Gallico $(1,1)$.

3 Brunaux, $1996: 63$.

4 Ibidem: 16.

5 Curiosamente, este espacio corresponde a la actual región francesa de Picardía, lo que induce a pensar que las fronte- ras actuales distorsionan, de cara a la investigación arqueológica, las áreas culturales, que se ven drásticamente reducidas y reformadas.

6 Brunaux, 2004: 14. 
En una publicación más reciente centrada precisamente en la relación entre guerra y religión en la Galia prerromana ${ }^{7}$, el mismo autor recuerda, con gran acierto, que « no todas las regiones [de las Galias] se prestan igualmente al tipo de análisis que se plantea aquí », pero asegura incluso que « en Bretaña y en el CentroEste, los vestigios que se pueden asociar a las prácticas guerreras y a las manifestaciones cultuales son demasiado escasos para ser de valor alguno. De la misma manera, los lugares de culto del Centro-Este siguen siendo muy escasos, y aquellos que podrían ser identificados como tales son problemáticos o están aún en proceso de excavación. La Aquitania [...] parece demasiado pequeña para servir de base a este estudio. ${ }^{8}$ La mayoría de los trabajos que aluden a los ritos guerreros en la Segunda Edad del Hierro, naturalmente basados en las publicaciones de Brunaux ${ }^{9}$, han aceptado esta propuesta, de tal modo que apenas si hacen referencia a yacimientos del Sur de la Galia. Si bien otras síntesis sobre la religión gala ofrecen un panorama mucho más completo, aunque menos interpretativo, del conjunto del territorio francés, ${ }^{10}$ los santuarios belgas y sus correspondientes tipocronologías siguen siendo los principales referentes para describir contextos y objetos a menudo muy alejados en el espacio ${ }^{11}$ y a veces en el tiempo.

La escasa concentración tanto de yacimientos (para este trabajo se han inventariado un total de 14 frente a 16 tan sólo en la Galia Bélgica) como de armamento en contextos rituales (55 piezas forman el conjunto más grande) ha representado el principal escollo para el estudio global de los ritos de armas en la mitad Sur de la Galia. Repartidos en 7 regiones actuales, la mayor dispersión geográfica de los yacimientos no ha favorecido, como en el caso de la Galia Bélgica, su estudio en el seno de un mismo equipo ni la reunión de sus publicaciones en torno a mesas redondas y coloquios ${ }^{12}$. Su distribución temporal, irregular entre el s. IV y el s. I a. C., ofrece

7 Brunaux, 2004.

8 Ibidem: 12.

9 Webster, 1996 ; Gabaldón, 2004.

10 Arcelin y Brunaux (Dir.), 2003.

11 Poux, 2004 ; Roure, 2009. sin duda una imagen menos homogénea e impide que se vincule su aparición con un fenómeno preciso y bien definido. Sin embargo, hasta ahora, no se ha tratado de analizar la divergencia que separa, precisamente, la mitad Sur de la Galia del conjunto, ampliamente estudiado de la Galia Bélgica.

El objetivo originario de este trabajo es contribuir a llenar el vacío historiográfico constatado en esta zona, realizando una recopilación de los yacimientos en los que han aparecido piezas de armamento en contextos cultuales con el fin de desarrollar una reflexión global acerca de este fenómeno en el conjunto del Sur de la Galia. Parte integrante de este enfoque es la comparación con los estudios dedicados a la Galia Bélgica. En este sentido, un aspecto fundamental será la puesta en cuestión del paradigma de los "santuarios belgas", adoptando una posición crítica en cuanto a su definición, su distribución espacio-temporal y la validez de su empleo como modelo representativo del papel ritual de las armas en la Galia de la Segunda Edad del Hierro. En definitiva, se planteará la problemática de la diversidad de los ritos de armas en el amplio territorio galo, tratando de distinguir los patrones generales que rigen este fenómeno.

La perspectiva historiográfica de este enfoque justifica precisamente la delimitación geográfica que se ha adoptado (v. fig. 2). El trabajo de síntesis de M. Gabaldón ha servido de ejemplo del vacío historiográfico que padece toda la mitad Sur de la Galia, en la medida en que su estudio se limita prácticamente al territorio situado al Norte de dos santuarios especialmente relevantes, los de Muron (Charente-Maritime) y Mirebeau-sur-Bèze (Côte-d'Or). Se ha empleado esta observación para trazar una línea entre ambas localidades ${ }^{13}$ como límite Norte de este estudio. En dirección Este hemos atribuido valor de frontera cultural a una línea Norte-Sur próxima al Ródano que constituiría una prolongación

\footnotetext{
12 Brunaux (Dir.) 1991, Brunaux (Dir.), 1996, Brunaux et alii, 2000.

13 Esta línea tiene una orientación Norte-Sur únicamente en los mapas físicos del territorio francés.
} 
del Rhin hacia el Sur. Del mismo modo, se ha excluido del estudio la zona inmediata a la costa mediterránea y su hinterland por considerarse que pertenece a un horizonte cultural diferente del resto de la Galia. Esta diferenciación se basa, por un lado, en la divergencia de sus contextos, ya que los santuarios del Sur-Este de la Galia, construidos en piedra y dotados de una escenografía, se rigen por criterios urbanos. La importancia de la estatuaria, por otro lado, prueba que los cultos guerreros se manifiestan de forma específica, lo que confirma una diferencia de naturaleza en el conjunto de las prácticas religiosas, profundamente mediterraneizadas, de este área. Curiosamente, puede observarse una peculiar ausencia de santuarios con armas en toda la zona que rodea a la costa mediterránea, a excepción del yacimiento de Le Cailar (Gard); una circunstancia que parece significativa para afianzar la frontera cultural que hemos marcado.
O C É A N O

A T L Á N T I C O

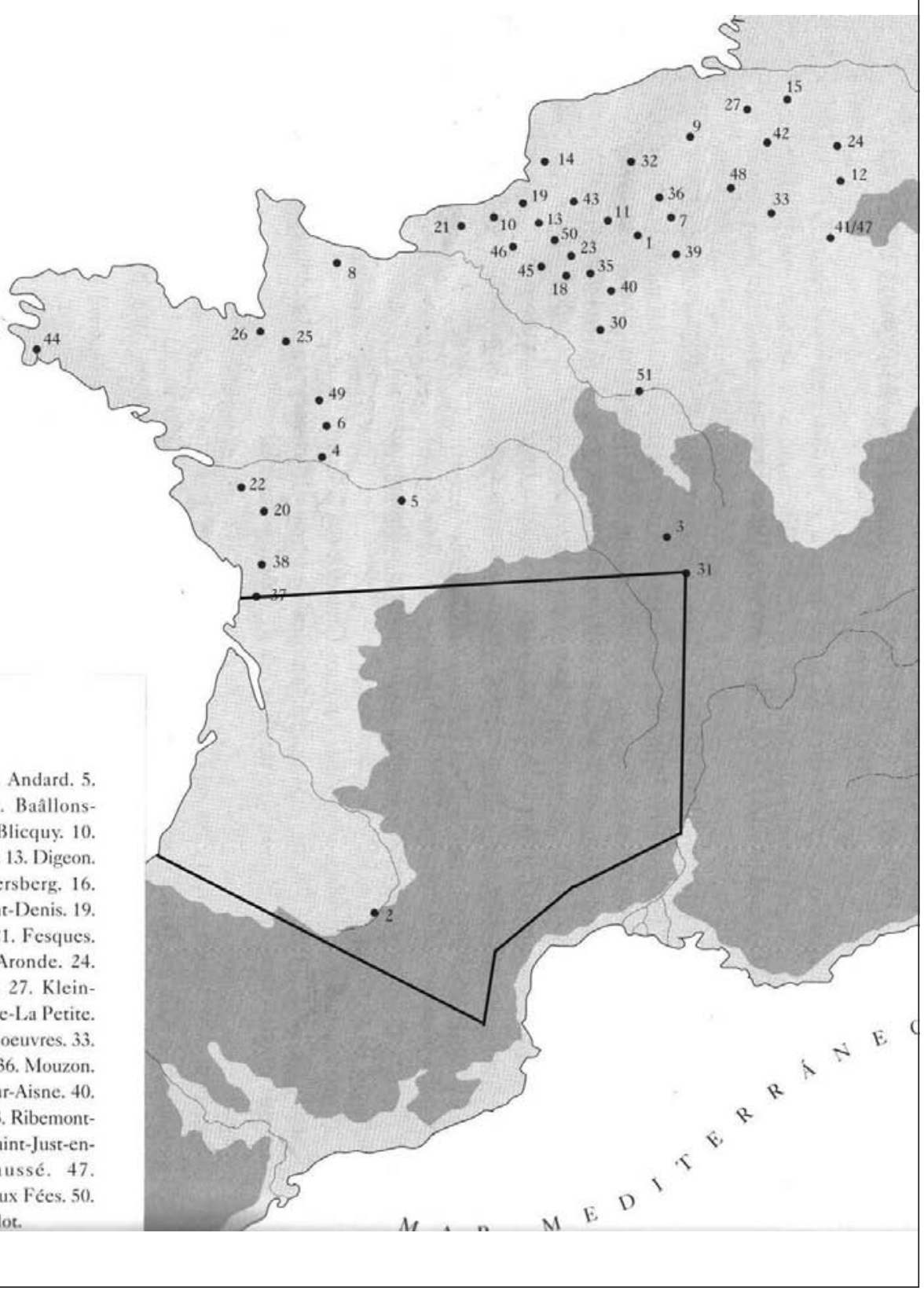

Figura 2. Mapa de los yacimientos de la Galia catalogados por Gabaldón (Gabaldón, 2004: 294), y zona de delimitación de nuestro estudio. 
La zona estudiada, de esta forma, se ha considerado como homogénea esencialmente desde el punto de vista de la necesidad de recopilación de datos respecto a los ritos de armas durante la Segunda Edad del Hierro. La presentación del catálogo de yacimientos considerados, servirá de base para evaluar los criterios de calidad, cantidad y funcionalidad de los depósitos de armas en sí y estudiar el papel del armamento en la determinación de patrones cultuales y culturales en el contexto de los santuarios.

\section{CATÁLOGO DE YACIMIENTOS}

La siguiente relación, que incluye toda clase de yacimientos en los que se han documentado armas en contextos rituales, es fruto de una aproximación bibliográfica a la cuestión, por lo que se ha confeccionado a partir de la información publicada. Mediante el estudio de ésta, se han privilegiado los criterios de contexto y tratamiento por encima de la cuantificación de las piezas de armamento. De este modo, se han considerado contextos cultuales los depósitos en conjuntos cerrados (fosas, pozos, depósitos en zonas naturales), asî como las estructuras de amortización (fosos y amasijos al aire libre) cuyas asociaciones y dispersiones de materiales difieren de patrones directamente funcionales y se relacionan con actividades simbólicas (no funerarias).

Las armas se han considerado como parte de dichas actividades en la medida en que se ha documentado su amortización voluntaria, ya sea mediante depósito o destrucción intencional, en las estructuras que responden a las características anteriores. No se han incluido en el estudio, por lo tanto, las armas halladas fuera de contexto, ya que, al no ofrecer información acerca de su empleo en el marco de actividades rituales, se considerarán únicamente como paralelos tipológicos de las piezas en contexto. Se han considerado sólo de manera secundaria los restos de carros, caballos y arreos, insignias e instrumentos musi-

14 Arcelin y Brunaux, 2003: 132.

15 Esencialmente, Boudet, 1996 recoge la mayor parte de la información tanto antigua como referente a las campañas de los años 1990-1993. No obstante su interpretación e incluso sus datos estratigráficos han sido revisados recientemente de manera crítica en Verdin y Bardot, 2007: 238.

16 Boudet, 1996. cales, ya que su relación, indirecta, con la actividad bélica está condicionada a su asociación con piezas de armamento.

\section{Agen (Lot-et-Garonne)}

El oppidum de l'Ermitage en Agen es un hábitat de la Segunda Edad del Hierro a orillas de la Garona en el que se han excavado varias estructuras que pueden clasificarse como "pozos del Sur Oeste" ${ }^{14}$. Conocido desde antiguo, parte de los datos de los que disponemos sobre este yacimiento son inciertos y su empleo como base de análisis resulta muy problemático ${ }^{15}$. En concreto, en 1879 se vació por primera vez un pozo, de planta circular, $1 \mathrm{~m}$ de diámetro y $11 \mathrm{~m}$ de profundidad, que se interpretó en aquel momento como una estructura funeraria. El relleno, en el que no se apreció una estratigrafía y parte de cuyo material se ha perdido, incluía un casco de hierro de tipo Mannheim que contenía, supuestamente, un cráneo humano. Se documentaron también un fragmento de hoja de espada, una punta de lanza, tres cuerpos completos de ánforas junto con otros restos cerámicos (cerámica común y una lucerna itálica), un cuchillo de hierro y 15 cráneos de ovicaprinos y 11 de bóvidos todos ellos perforados en la zona frontal. El conjunto puede fecharse de manera aproximativa en los decenios previos al cambio de era.

Hasta la intervención de R. Boudet ${ }^{16}$ a principios de los años 90, no se realizó una excavación científica con resultados similares. En este caso, se documentó intramuros un pozo denominado Z1 (v. fig. 3), que parece, no obstante, situarse al margen de la zona habitada y se fecha a mediados del siglo I a. C. Se trata de una estructura de planta cuadrangular de alrededor de $1 \mathrm{~m}$ de lado y $4,25 \mathrm{~m}$ de profundidad. En el fondo de la misma, se estrelló un vaso completo de tipo balustre ${ }^{17}$ de pasta fina, en torno al cual se dispusieron un casco de bronce de tipo Mannheim en posición invertida, dos hoces de hierro funcionales, un oinocoe decorado con una cabeza de sileno y otro vaso balustre.

17 "Vase balustre" es el término acuñado por la historiografía francesa para referirse a un tipo de recipiente característico de los facies cerámicos laténicos, cuya forma recuerda al elemento arquitéctonico que le da nombre. Se trata de formas cerradas, altas y de perfil sinuoso cuyo diámetro máximo se sitúa en la parte superior del cuerpo, inmediatamente debajo de un cuello corto y estrangulado. Estas producciones, muy cuidadas, están realizadas a torno. 


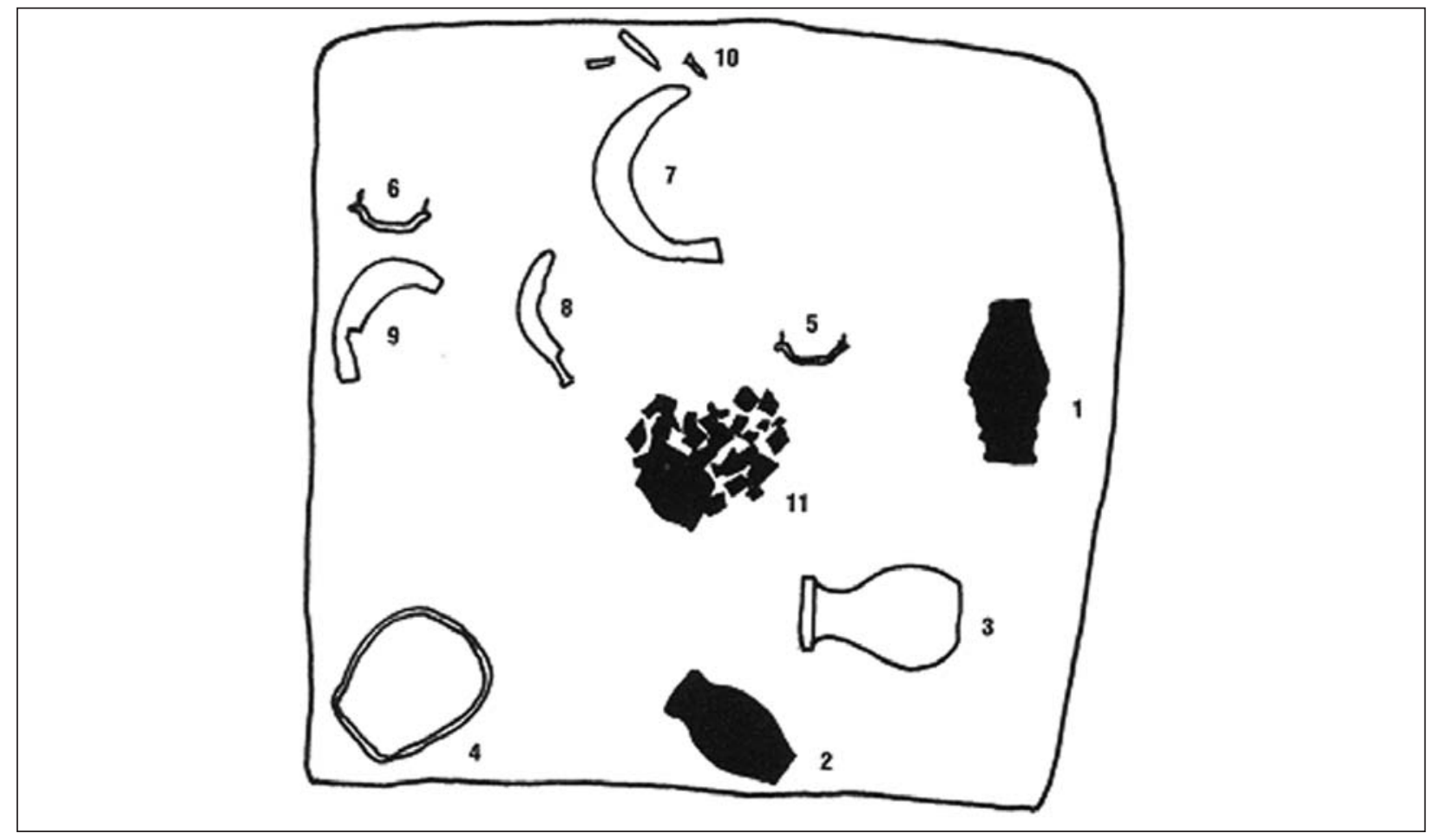

Figura 3. Depósito del pozo Z1, según Boudet, 1996: 76

En 1993, se excavó la estructura 41, un pozo de planta cuadrada de $1,80 \mathrm{~m}$ de lado y 7,50m de profundidad que alcanza la capa freática. Apareció asociado a un edificio de planta cuadrada sobre postes de madera interpretado como un santuario. $\mathrm{Su}$ relleno incluía restos de 50 ánforas Dressel Ia estrelladas con la punta hacia arriba en un mismo momento, según indica la homogeneidad de sus estampillas. En el fondo de la estructura, se distinguieron tres depósitos relacionados con el inicio de un recubrimiento de planchas de madera y la presencia de una cámara excavada en la roca. Estos incluían dos cascos de bronce de tipo Mannheim en posición invertida, cerámica local (recipientes completos y semi-completos), un oinocoe decorado, dos cubos de madera decorados con apliques de bronce, una sítula y un colador de bronce. El conjunto puede fecharse en torno a 80/60 a. C.

Boudet, 1996, Verdin y Bardot, 2004.

\section{Agris (Charente)}

La cueva denominada "Grotte des Perrats" en Agris, frecuentada desde el Mesolítico hasta la Edad Media, es un yacimiento aislado en el que se depositó uno de los cascos más complejos de la Europa de la Edad del Hierro. Se trata de una pieza excepcional, que se caracteriza por un timbre de hierro recubierto de una hoja de bronce decorada, dorada y en la que se incrustan varios centenares de fragmentos de coral. Junto con él, el conjunto de materiales de La Tène $B$ incluye tres fíbulas, un instrumento puntiagudo con un fragmento de mango de madera y un conjunto cerámico en el que predominan las producciones de calidad.

Gómez de Soto, 1991; Gómez de Soto, Milcent et alii., 2003.

\section{BESANÇON (DOUbS)}

A raíz de una excavación de urgencia en la Plaza del Ayuntamiento, se halló en el oppidum de Vesontio, capital de los Secuanos, un amplio sector de hábitat. Se trata de un contexto excepcional que cubría alrededor de 4000m2, con depósitos de restos faunísticos de caza y elementos de prestigio: cascos, espuelas, torques, una fíbula de plata, y restos de ánforas itálicas muy abundantes. La hipótesis de un vertedero queda descartada por la calidad y la cantidad de los materiales concentrados en diferentes estructuras negativas. Se asocian a dos edificios sobre postes de madera interpretados como viviendas aristocráticas cercanas a un foso defensivo, fechado entre La Tène final y época altoimperial. Su naturaleza votiva, que no ha sido explorada por los excavadores, es una propuesta que permite explicar el carácter excepcional de estos depósitos.

V. V. A. A. 1992. 


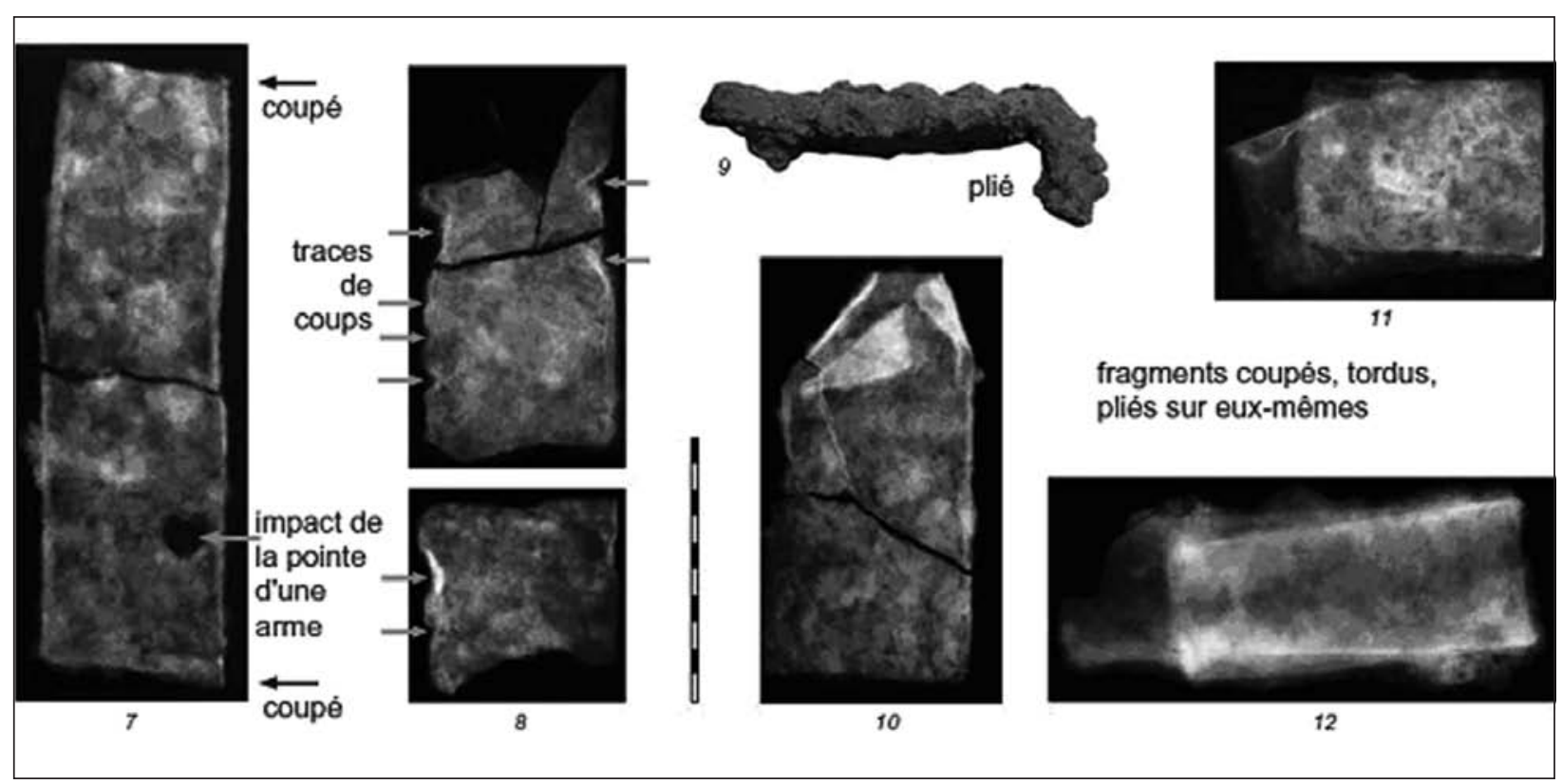

Figura 4. Marcas de mutilación voluntaria (golpes, impactos, cortes y pliegues) en vainas del depósito de Le Cailar. Girard y Roure, 2007.

\section{Le Cailar (Gard)}

A pesar de su localización en el Languedoc oriental, muy próximo a la costa mediterránea, este yacimiento parece pertenecer claramente al conjunto que nos ocupa, tanto por su contexto, como por su material metálico y el tratamiento al que fue sometido. Consiste en un depósito poco organizado del siglo III a. C. (con una duración de unos 75 años según la cronología cerámica) que ocupa alrededor de $70 \mathrm{~m}^{2}$ y se localiza pegado a la muralla, junto a la entrada del hábitat. Hasta 2007, se habían documentado en torno a 4000 restos, principalmente fauna, restos de cráneos humanos, cerámica común local, fina importada y ánforas masaliotas, así como monedas y otros 132 objetos metálicos (NMI). Más del $30 \%$ de éstos corresponde a armamento (lanzas, espadas y escudos) y complementos relacionados (vainas y cadenas de suspensión). Las piezas de armamento presentan frecuentemente señales de mutilación voluntaria, aplastamiento, pliegues, fracturas, cortes y perforaciones (v. fig. 4). Las espadas y las vainas son los elementos más afectados, ya que ninguna pieza de estas categorías se ha hallado entera e intacta.

Roure y Girard, 2007, Roure, 2009.

\section{Cleppé (Loire)}

Hallado bajo los restos de una capilla del siglo XI al borde del Loira, este conjunto de fosos galo se interpreta como un santuario de en torno a 1 ha. Se trata de un doble recinto cuadrangular orientado a los cuatro puntos cardinales en cuyo foso Norte se hallaron dos umbos de escudo mutilados (presentan perforaciones), varios elementos de carro (anillo pasador y placas de hierro), vajilla de bronce y restos anfóricos (Dressel I) muy abundantes fechados en La Tène D1-D2.

Barral et alii, 2003

\section{Corent (Puy de Dôme)}

En el oppidum arverno de Corent se localiza un gran santuario fechado entre mediados del s. II a. C y mediados del s. I a. C muy rico en material arqueológico. Su componente principal es un recinto cuadrangular delimitado por un foso de $50 \mathrm{~m}$ de lado completado por una empalizada (v. fig. 3). En el eje de la entrada, se sitúan una serie de fosas y "altares huecos" destinadas a ofrendas y libaciones, así como una gran piedra de altar de basalto. En su interior, otros dos pequeños edificios sobre postes prácticamente idénticos se interpretan como edículos cultuales. 
Hasta el momento, sorprendían los parecidos de Corent con los santuarios de la Galia Bélgica ${ }^{18}$, a excepción de la patente ausencia de armas en el yacimiento arverno. Recientemente, no obstante, un sondeo en una zona no excavada bajo la fase romana (santuario tipo fanum situado en el eje de la entrada del recinto galo) ha permitido localizar un depósito excepcional compuesto por cuatro umbos de escudo, un importante fragmento de cota de malla de hierro prácticamente intacta y un posible elemento de insignia de bronce, una franja con decoración calada que puede corresponder a la cresta de un jabalí. ${ }^{19}$ Se ha interpretado este conjunto como un trofeo por su similitud con las fuentes iconográficas de época romana.

El resto de los materiales del yacimiento son excepcionales tanto por su cantidad como por su calidad. Incluyen miles de fragmentos anfóricos seleccionados, frecuentemente derivados de una "decapitación" de las ánforas aún llenas, y depositadas semi-completas, confirmando la importancia de los ritos de libación, en especial relacionados con estructuras en negativo como fosas delimitadas en la superficie por grandes fragmentos de panzas anfóricas. Los restos de fauna, entre los que destacan los fragmentos craneales perforados, corresponden a despojos de banquetes (en el foso), ofrendas sacrificiales (fosas con miembros completos) y elementos decorativos seleccionados y colocados intencionalmente (en torno a los dos edificios). La vajilla cerámica y de bronce, junto con los instrumentos de sacrificio y despiece (cuchillos de hierro) confirman el empleo del recinto para la celebración de banquetes.

Poux 2000, Poux 2004, Poux y Foucras 2008

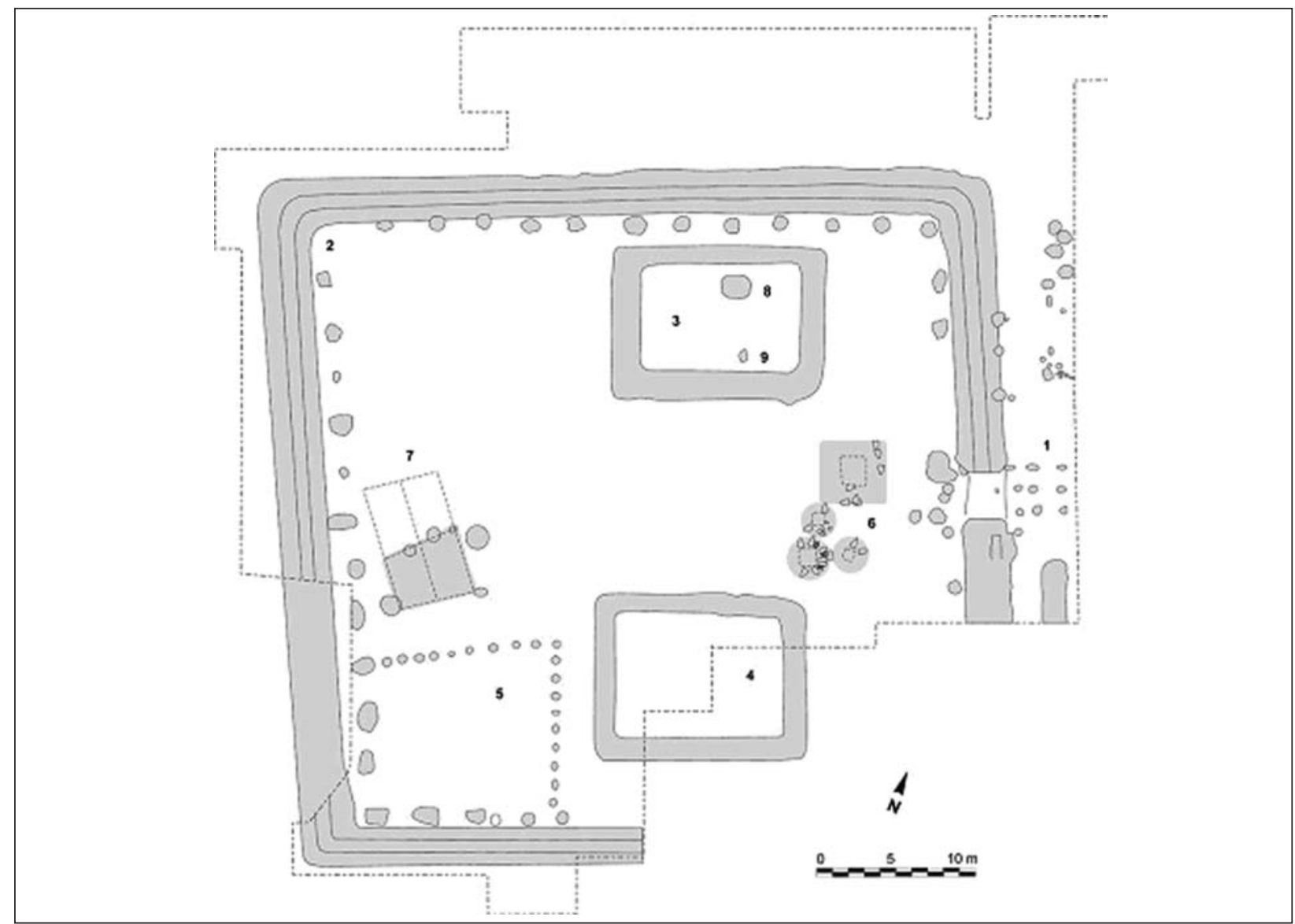

Fig. 5. Plano simplificado del santuario de Corent (Puy-de-Dôme). 1. Porche de entrada ; 2. Peribolos : foso de implantación de la empalizada de madera (primera fase) y de los agujeros de poste de la galería de madera (segunda fase) ; 3. Edificio Norte ; 4. Edificio Sur ; 5. Recinto para ganado ; 6. Fosas libatorias ; 7. Edificio sobre postes ; 8. Fosa sacrificial ; 9. Piedra de altar. Poux y Foucras, 2008 : 164.

\footnotetext{
18 Poux 2004: 500.

19 Identificado mediante un paralelo en el jabalí-insignia de Soulac-sur-Mer (Gironde, Aquitania).
} 


\section{Courcoury (Charente-Maritime)}

En el s. VI a. C., el yacimiento de Courcoury consiste en un enorme túmulo que alberga una tumba aristocrática de incineración cuyo rico ajuar incluye un recipiente etrusco y un kylix masaliota. En un momento posterior, indeterminado, se excavan varios fosos en torno al túmulo, que albergan ofrendas faunísticas y materiales de prestigio del s. IV, por lo que se identifica como un santuario relacionado con la tumba. En el foso periférico, aparecieron cráneos de caballo y bóvidos asociados a un fragmento de espada.

Gómez de Soto, Milcent et alii., 2003.

\section{CAMP de Larina (ISÈre)}

El depósito del Camp de Larina se localizó mediante sondeos al pie y al fondo de una falla ${ }^{20}$ natural pantanosa en las inmediaciones de un hábitat fortificado al borde del Ródano. La acumulación de objetos se realizó durante un periodo amplio, desde el Bronce Final hasta el final de La Tène D1, pero todas las piezas de armamento corresponden a la Segunda Edad del Hierro. El conjunto material atribuible al intervalo La Tène B2-La Tène D2 consta de cerámica local y 339 objetos metálicos, esencialmente utensilios genéricos (punzones, cinceles, agujas, hachas, etc...), agrícolas (láminas de hoz) y culinarios (fragmentos de tenedores, grills, cuchillos y sítulas de bronce), elementos de adorno personal (fíbulas y brazaletes de bronce). Las armas son minoritarias en este depósito, ya que se reducen a una espada, una vaina, tres umbos de escudo y una punta de lanza o jabalina. Sin embargo, podemos incluir también en la planoplia de guerrero dos restos de placas identificadas como elementos de carro y un fragmento de bocado de caballo.

Perrin 1991, Barral et alii 2003.

\section{Mandeure (Doubs)}

Mandeure es un hábitat galo ocupado desde La Tène D2, y que desde principios del s. I adopta todas las características de una ciudad romana. A las afueras de la aglomeración, se encuentra un importante complejo cultual, bajo el que apareció,

${ }^{20}$ Una denominación alternativa de este yacimiento, frecuente en la bibliografía, es "la faille de la Chuire".

${ }^{21}$ En particular, se cuenta entre los hallazgos un posible fragmento de una cresta de jabalí con decoración calada similar a principios del siglo $\mathrm{XX}$, un depósito galo (La Tène C2-D1 son las fases mejor representadas). $\mathrm{Su}$ aspecto más espectacular es la extraordinaria acumulación de objetos de vidrio (brazaletes y perlas) con el que debe relacionarse, sin duda, la abundancia de otros objetos de adorno como fíbulas Nauheim. El número de armas y sus complementos hallados en este contexto es claramente menos importante: asciende a 23 , un fragmento proximal de una espada con su vaina, tres puntas de lanza y una de jabalina, tres talones de armas de asta y catorce hebillas de cinturón. Debe considerarse la presencia, además, de objetos relacionados con la guerra, fragmentos de animales en bronce $^{21}$, posiblemente insignias militares, así como los restos de carnyx en forma de jabalí aparecidos en el mismo santuario.

Barral, 2007

\section{Mirebeau-Sur-Beze (Côte-D’Or)}

La zona del Bèze se considera como el área de confluencia de los lingones, los secuanos y los eduenos, los tres principales pueblos de la Galia del Centro-Este. No resulta sorprendente, por lo tanto, que este espacio fuera utilizado como santuario desde el siglo IV hasta época romana (fanum doble). El armamento aparece desde la primera fase (s.IV-mediados del s. II), en el que varios fosos de planta trapezoidal albergan restos de espadas voluntariamente fragmentadas. Durante la fase de apogeo del santuario (segunda mitad del s. II), la densidad de estructuras en el interior del recinto aumenta considerablemente, mediante la excavación de numerosas fosas de ofrendas y la construcción de un edificio sobre postes. De forma paralela, las categorías de ofrendas aumentan y se diversifica: a las espadas se añaden vainas y sus remates, escudos y puntas de lanza. Al margen de los despojos culinarios faunísticos, aumentan las cerámicas de lujo, ánforas, vasos en miniatura, las herramientas variadas, y los depósitos monetarios. El sacrificio del armamento es especialmente evidente en esta fase: son recurrentes los pliegues en las espadas, vainas y puntas de lanza, la fractura en las espadas y el desmonte minucioso de escudos y remates de vaina. En la fase final de La Tène, el lote de armamento

a las de las insignias de Soulac-sur-Mer (Gironde, Aquitania) y Corent. 
es especialmente numeroso y aparece concentrado en fosas o favissae junto con ofrendas alimenticias, fíbulas y otros objetos de adorno de vidrio.

Barral y Joly, 2003

Joly, Duperé, Logereau, 2009

\section{Muron (Charente-Maritime)}

El hábitat de Muron es un importante yacimiento de la Segunda Edad del Hierro que incluye un sector de producción sal, una necrópolis y un santuario. Este último corresponde a un conjunto de fosos de delimitación de áreas empedradas. El espacio del santuario, mal delimitado (por un foso al Este) se caracteriza también por numerosas fosas con un rico material fechado en La Tène C2 y D1. Las armas están bien representadas con una centena de ejemplares, repartidos fundamentalmente entre espadas y vainas, y, en menor medida, puntas de lanza. Las tres categorías aparecen afectadas por mutilaciones voluntarias. El resto de los materiales incluye monedas, restos de fauna, cerámica de buena factura y gran cantidad de herramientas metálicas.

Gómez de Soto y Lejars 1991, Gómez de Soto, Milcent et alii, 2003.

\section{Tintignac (CORRÈze)}

El santuario de Tintignac es un recinto cuadrangular de $24 \mathrm{~m}$ de lado delimitado por un foso y una serie de agujeros de poste excavados en él, destinados a la colocación de una empalizada perimetral. El conjunto, sobre el que se implantó un fanum doble en época altoimperial, está rodeado de una banda empedrada de $8 \mathrm{~m}$ de ancho. En su esquina Sureste se localizó, además, un pequeño edificio sobre cuatro postes interpretado como una dependencia relacionada con el culto. No se han encontrado armas en el curso de la excavación, aún parcial, del conjunto del santuario, a excepción de una fosa localizada en el ángulo Noreste del recinto.

Se trata de una estructura poco profunda (30 $\mathrm{cm})$, de planta cuadrada con ángulos redondeados, en la que han aparecido más de 500 fragmentos de objetos metálicos. De los 492 fragmentos de objetos identificados, 148 pertenecen a vainas de hierro, 42 a hojas de espadas, 17 a vainas o espadas indiferenciables, 11 a puntas de lanza, 1 umbo de escudo y 33 fragmentos de cascos correspondientes a 10 piezas completas. Esta categoría llama especialmente la atención por el carácter excepcional de algunos de los ejemplares depositados: incluyen un casco en forma de cisne y tres cascos decorados respectivamente con anillos, frisos $\mathrm{y}$ rejilla de bronce. La panoplia guerrera queda completada por dos fragmentos de arreos de caballo y 7 discos de bronce (adornos de arreos o quizá discos de coraza). El depósito contenía, además, un caldero completo, 22 fragmentos de carnyx, 4 restos de cabezas de animales de bronce (dos jabalíes, un caballo y un animal no identificado) y 10 fragmentos correspondientes a las patas y el cuerpo de dichos animales. En todos los casos, su tamaño es suficientemente importante para poder aceptar la hipótesis de insignias zoomorfas.

El capítulo del tratamiento es especialmente interesante en este yacimiento: el depósito aparece claramente organizado, reposando el casco en forma de cisne junto con la mayor parte de los fragmentos de carnyx en el fondo de la fosa. Sobre éstos se depositaron los otros 9 cascos, los arreos de caballo, e inmediatamente después, los fragmentos de animales y el caldero en hoja de bronce. Encima de éstos, los discos de bronce aparecieron por parejas, junto con las dos cabezas de jabalí. El siguiente lote lo forman varios fragmentos de animales y el umbo de escudo. Finalmente, se posaron nueve espadas con sus respectivas vainas en horizontal, depositadas separadas de todo elemento de suspensión en la superficie de la fosa y junto a un número similar de puntas de lanza. Antes de proceder al enterramiento ordenado de los objetos, éstos fueron sometidos, además, a importantes mutilaciones: la mayoría de las espadas y vainas aparecen partidas en dos y el umbo de escudo presenta numerosos golpes asestados con un objeto contundente, al igual que el caldero y varios cascos aplastados por un gran bloque de eclogita hallado in situ. Prácticamente todos los objetos complejos fueron objeto de un desmonte: es el caso, sin duda, de los animales de bronce y los carnyce, pero también el umbo de escudo fue depositado aislado del resto de la pieza, y la mayor parte de las paragnatidas fueron arrancadas de los cascos, de los cuales sólo cinco conservan sus cubre-nucas.

Maniquet, 2008.

\section{Vic-Fezensac (Gers)}

En el oppidum de Saint-Jean-de-Castex (VicFezensac), se ha documentado un pozo de de sección circular de una decena de metros de profundidad, fechado en torno a 20-10 a. C., cuyo relleno incluía un casco de bronce de tipo céltico tardío occidental sin paragnatidas, transfor- 
mado en sítula mediante un asa de hierro, ánforas Dressel I y Pascual I, así como varios instrumentos agrícolas.

Gómez de Soto, Milcent et alii, 2003.

\section{Vieille-Toulouse (Haute-Garonne)}

En algunos de los pozos del oppidum de Vieille-Toulouse, que se distribuyen por todo el espacio habitado, han aparecido piezas de armamento. En concreto, en el pozo XVI, de sección cuadrada y $11,30 \mathrm{~m}$ de profundidad, el depósito, fechado en el tercer cuarto del s. I a. C. y situado sobre la base de la estructura, incluía dos cascos de bronce de tipo Coolus-Mannheim (uno de ellos de bronce fundido, clasificado dentro de la "variante pesada" por Feugère, 1994: 43) en posición invertida. Formaban parte del mismo conjunto una punta de lanza, una hoz, diversos recipientes cerámicos completos (producciones finas locales, importaciones itálicas comunes y de barniz negro, un ánfora Dressel I) y elementos de vajilla de bronce (un caldero y dos sítulas de bronce). La capa que contenía lo esencial del material aparece sellada por una importante masa de restos vegetales y faunísticos (en la que aparecieron también una decena de monedas, un broche de cinturón y varías fíbulas), una capa muy rica en fragmentos anfóricos y un cierre de cantos fluviales a partir del cual el pozo se estrecha y se regulariza considerablemente.

Un caso similar es el del pozo XXIII, en cuyo fondo, a $8 \mathrm{~m}$ de profundidad, aparecieron tres cascos de características idénticas y en la misma posición que los ejemplares del pozo XVI. Los acompañaban, igualmente, seis sítulas de bronce y un fragmento de arreo de caballo. El depósito quedó sellado por una capa de residuos vegetales de $2 \mathrm{~m}$ de espesor, recubierto a su vez por un relleno rico en restos ánforicos y cerámica campaniense que han permitido datar la estructura en torno a 75/50 a. C.

Pailler, 2002; Gómez de Soto y Milcent, et alii, 2003; Gorgues, 2005
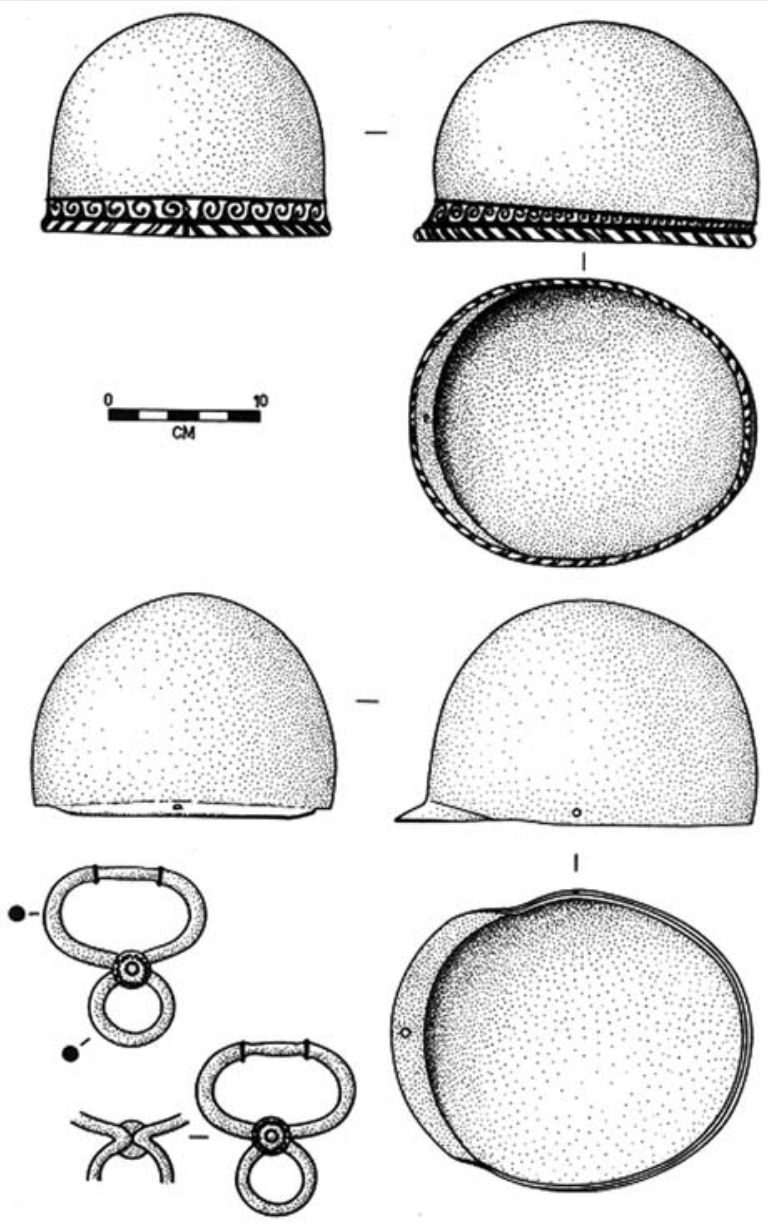

Figura 6. Cascos de tipo Coolus-Mannheim (arriba : variante pesada), con elementos de suspensión, procedentes del pozo XVI de Vieille-Toulouse. Feugère, 1994: 44. 


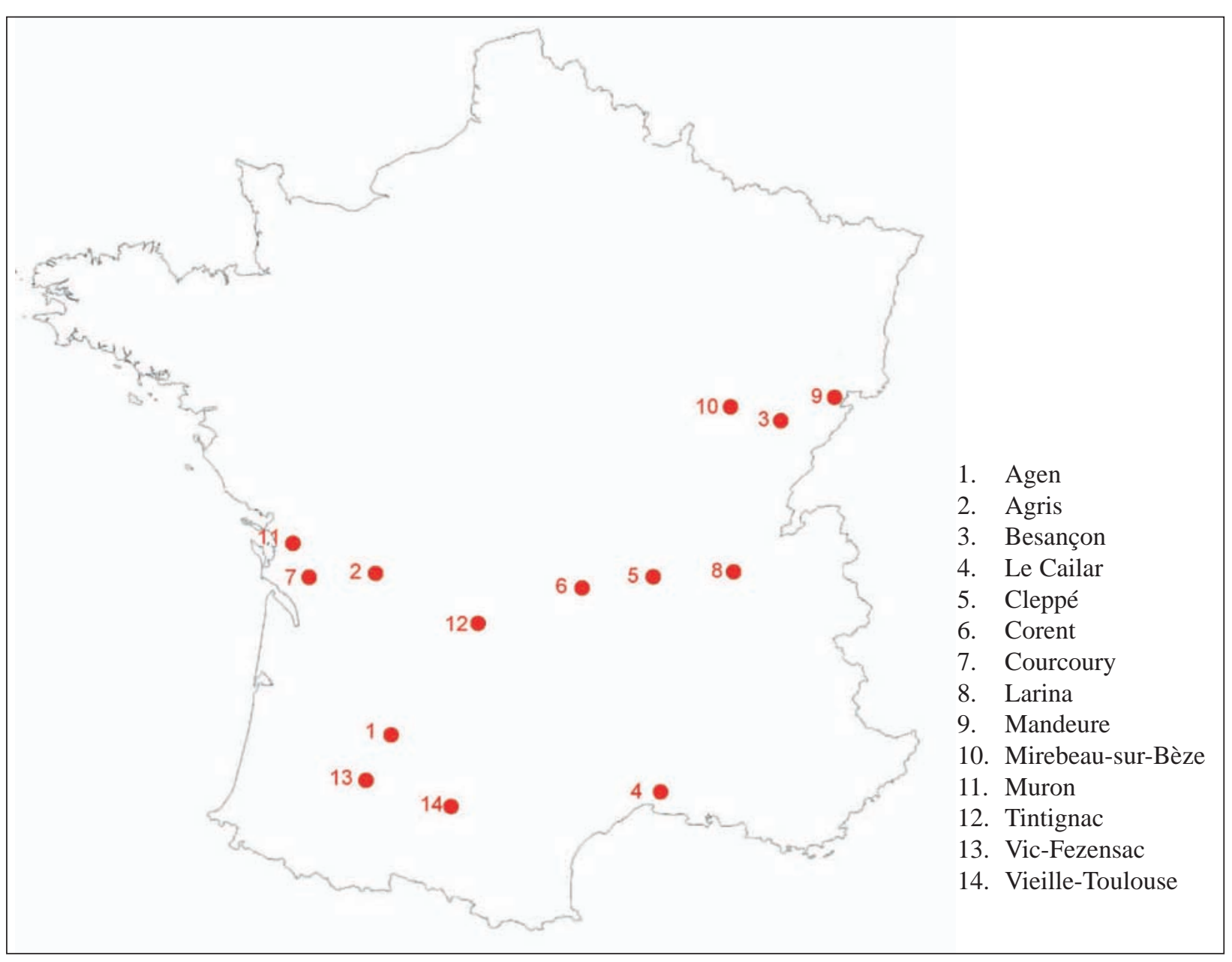

Figura 7. Mapa de los yacimientos mencionados. Creado mediante el programa GeCaFLi www.lion1906.com

\section{Cronología}

\begin{tabular}{|c|c|c|c|c|c|}
\hline & La Tène B & La Tène $\mathrm{C} 1$ & La Tène $\mathrm{C} 2$ & La Tène D & galorromano \\
\hline Agen & & & estruct. 41 & Z1 & pozo 1879 \\
\hline Agris & $\begin{array}{c}\text { frecuentación } \\
\text { de la cueva }\end{array}$ & & & & \\
\hline Besançon & & & & $\begin{array}{c}\text { hábitat de } \\
\text { prestigio }\end{array}$ & \\
\hline Le Cailar & $\begin{array}{l}\text { entrada de } \\
\text { hábitat }\end{array}$ & & & & \\
\hline Cleppé & & & & santuario & \\
\hline Corent & & & santuario & santuario & \\
\hline Courcoury & $\begin{array}{l}\text { recinto } \\
\text { cultual }\end{array}$ & & & & \\
\hline Larina & & depósito & depósito & & \\
\hline Mandeure & & & depósito & depósito & \\
\hline Mirebeau & & & santuario & santuario & \\
\hline Muron & & & santuario & santuario & \\
\hline Tintignac & & santuario & santuario & santuario & \\
\hline Vic-Fezensac & & & & pozo & \\
\hline Vieille-Toulouse & & & & pozos & \\
\hline
\end{tabular}


Tipos de armas

\begin{tabular}{|l|l|l|l|l|l|l|c|}
\hline & \multicolumn{3}{|c|}{ Armamento ofensivo } & \multicolumn{3}{c|}{ Armamento defensivo } & Otros \\
\hline Agen & espada & & lanza & cascos & & & \\
\hline Agris & & & & casco & & & espuelas \\
\hline Besançon & & & & cascos & & & carro \\
\hline Le Cailar & espadas & & & & escudos & & insignia \\
\hline Cleppé & & & & & escudos & & Caballo \\
\hline Corent & & & & & escudos & cota de malla & \\
\hline Courcoury & espada & & & & & & $\begin{array}{c}\text { Carnyx, } \\
\text { insignia }\end{array}$ \\
\hline Larina & espada & vaina & lanza & & escudos & & $\begin{array}{c}\text { Arreo de } \\
\text { caballo }\end{array}$ \\
\hline Mandeure & espada & vaina & lanza & & & & $\begin{array}{c}\text { Arreo de } \\
\text { caballo }\end{array}$ \\
\hline Mirebeau & espadas & vainas & lanzas & & escudos & & $\begin{array}{c}\text { carnyx, } \\
\text { insignias }\end{array}$ \\
\hline Muron & espadas & vainas & lanzas & & & & \\
\hline Tintignac & espadas & vainas & & cascos & & & \\
\hline Vic-Fezensac & & & & cascos & & & \\
\hline Vieille-Toulouse & & & & cascos & & & \\
\hline
\end{tabular}

Importancia relativa del armamento respecto al material metálico asociado (NMI) ${ }^{22}$.

\begin{tabular}{|l|c|c|}
\hline & NMI metal & Proporción del armamento \\
\hline Agen & & \\
$-\quad 1879$ & 4 & $75 \%$ \\
$-\quad$ Z1 & 4 & $25 \%$ \\
$-\quad$ St 41 & 6 & $30 \%$ \\
\hline Agris & 5 & $20 \%$ \\
\hline Besançon & medio & baja \\
\hline Le Cailar & 132 & $40,6 \%$ \\
\hline Cleppé & reducido & baja \\
\hline Corent & 6 & $83,4 \%$ \\
\hline Courcoury & reducido & baja \\
\hline Larina & 339 & $3,2 \%$ \\
\hline Mandeure & medio & baja \\
\hline Mirebeau & medio & media \\
\hline Muron & medio & media \\
\hline Tintignac & 56 & $66 \%$ \\
\hline Vic-Fezensac & 4 & $25 \%$ \\
\hline Vieille-Toulouse & & \\
- XVI & 7 & $28,5 \%$ \\
- XXIII & 10 & $30 \%$ \\
\hline
\end{tabular}

22 Para algunos yacimientos, las cifras precisas no han podido obtenerse. En esos caso, se ha estimado el NMI en reducido (inferior o igual a 10), medio (varias decenas) o elevado (100 o más). La proporción de armas se ha clasificado de la siguiente manera: baja (menos del 25\%), media (entre $25 \mathrm{y}$ $50 \%$ ), alta (entre 50 y $75 \%$ ) y muy alta (más del $75 \%$ ). 


\section{CANTIDAD, CALIDAD Y FUN- CIÓN DE LOS DEPÓSITOS DE ARMAS.}

\section{Categorías de depósitos en función DE SUS PROPORCIONES: ¿UN BUEN CRITE- RIO?}

El análisis de los depósitos metálicos de La Tène ha sido objeto de discusión recientemen$\mathrm{te}^{23}$, siendo la propuesta más interesante la realizada por J. P. Guillaumet y G. Bataille ${ }^{24}$. Su método parte de la clasificación de los conjuntos metálicos siguiendo tres criterios principales: su abanico cronológico, su NMI, las proporciones de objetos adscritos a las principales categorías funcionales respecto al NMI y, en menor medida, el NMO de cada objeto (número mínimo de objetos en el que se cuentan fragmentos importantes de objetos complejos como remates de vaina). El objetivo es definir grupos cronológicos, de tamaños y de categorías dominantes con el fin de identificar patrones fijos de depósito. Siguiendo estos criterios, el estudio del material metálico de Le Cailar ha permitido clasificar este conjunto en una serie de depósitos fechados en La Tène B2 compuestos por más de un centenar de objetos entre los cuales predomina claramente el armamento ${ }^{25}$.

De una forma más esquemática, nos hemos inspirado de esta propuesta para clasificar los conjuntos de armas analizados en este trabajo, que incluyen, significativamente, casos más recientes que la mayoría de los estudiados por Bataille y Guillaumet. Nos encontramos ante los mismos problemas de base: la dificultad, en ocasiones, de cuantificar conjuntos que están publicados sólo parcialmente, y la baja representatividad de los conjuntos demasiado pequeños. De este modo, la mayor parte de éstos pueden clasificarse, desde un punto cuantitativo, como reducidos, con un NMI igual o inferior a 10. Un segundo grupo, que incluiría probablemente Mirebeau y Mandeure, tendría un NMI de varias decenas. Sólo Le Cailar, Larina y Muron pueden considerarse como yacimientos ricos en materiales metálicos, que incluirían más de un centenar de objetos. En este sentido, resulta significativo que no siempre los conjuntos que cubren un abanico cronológico amplio, como Larina, son los que más objetos metálicos albergan, puesto que Le Cailar, que abarca un período breve de tiempo, se encuentra en la misma categoría. Concluimos, a diferencia de Bataille, que el tiempo de deposición es heterogéneo en cada yacimiento y en cada fase del mismo.

En cuanto a la composición de los conjuntos metálicos, nuestro corpus demuestra que, en los casos más reducidos, como algunos de los que Bataille analiza ${ }^{26}$, la proporción de armas es anormalmente elevada, por lo que falsea el resultado. Por otra parte, su hipótesis ${ }^{27}$, según la cual durante La Tène B los depósitos metálicos estarían dominados por el armamento, sólo se ve refrendada parcialmente por nuestro elenco. Si bien queda confirmado que, tanto en términos absolutos como proporcionales, las armas ocupan un lugar privilegiado en el material metálico de Le Cailar, no es el caso de otros yacimientos contemporáneos como la grotte des Perrats en Agris o Courcoury. Del mismo modo, el predominio de las herramientas en los momentos más recientes de La Tène ${ }^{28}$, se confirma en el caso de los pozos del Suroeste, en los que, sin embargo, resulta mucho más llamativo el aumento de la vajilla de bronce. Esta observación permite extraer conclusiones funcionales en cuanto a los depósitos de armas en contextos cultuales, que discutiremos más adelante.

Puede considerarse de este modo que la utilidad del método de Bataille debe matizarse para este estudio. Efectivamente, funciona bien en yacimientos que cumplen dos requisitos: su número de objetos de metal es muy elevado y éstos resultan especialmente significativos desde un punto de vista cualitativo (cronología, adscripción cultural, social, etc) como en el ejemplo del santuario de Villeneuve-au-

\footnotetext{
23 Bataille y Guillaumet (Dirs), 2006.

24 Bataille, 2006: 247.

25 Roure y Girard, 2007.

26 Cernov, Pohanská II y III, Bataille, 2006: 248-250.

27 Ibidem: 254.
28 Ibidem.
} 
Châtelot (Champagne-Ardenne) al que Bataille dedicó su tesis doctoral ${ }^{29}$. Al intentar aplicarlo a depósitos metálicos, en su mayoría fuera de contexto, se olvida de que en muchos de ellos el metal no es la única categoría de material: es el caso de Larina ${ }^{30}$, cuyo conjunto cerámico no puede obviarse. En algunos de nuestros yacimientos, el metal es una categoría minoritaria, pero aunque no lo fuera, entenderla como un ensamblaje aislado del resto de indicios nos parece más un retroceso metodológico que una innovación. Por otro lado Bataille pretende que su enfoque combine los aspectos cuantitativo y cualitativo $^{31}$ y sin embargo éste último ve reducida su utilidad a la clasificación tipológica que permite definir las categorías a cuantificar. Sin ánimo de resultar positivista, parece insostenible, no obstante, considerar de la misma forma un casco de Agris y cualquier espada de La Tène. Si aceptamos que la cuantificación es una herramienta de análisis interesante a la hora de estudiar los conjuntos metálicos, para evitar aplicar categorías arbitrarias a los yacimientos arqueológicos, debemos también analizar el papel del esfuerzo técnico y simbólico del depósito en contexto ritual, es decir, su calidad.

\section{El CONCEPTO DE CALIDAd DEL ARMA- MENTO EN CONTEXTOS Rituales DEL SUR DE la Galia.}

Los contextos cultuales, tal y como los hemos definido, se caracterizan por regirse en función de criterios ajenos a lo económico y lo práctico. La cantidad de hallazgos, así como su composición funcional no permiten acceder al empleo del concepto de calidad técnica y simbólica, que sólo puede reflejarse mediante el estudio de los conjuntos en función de la presencia, homogeneidad, cuantificación, posición, procedencia, etc... de objetos excepcionales no necesariamente en sí mismos sino también en el contexto cultual de la Segunda Edad del Hierro en territorio galo. Los conjuntos considerados en este trabajo se prestan especialmente a esta clase de análisis precisamente por su escasez.
La abundancia de los facies metálicos del Norte de la Galia ha generado un enfoque reduccionista al que, precisamente, nos oponemos en este trabajo. Gran parte del interés y la singularidad de los yacimientos de la zona sur de la Galia radica precisamente en la sobre-representación de características cualitativamente excepcionales en los conjuntos de armamento de La Tène.

Los objetos más frecuentes que componen estos hallazgos son las espadas, que aparecen, efectivamente, en 8 de los 14 yacimientos y forman lo esencial de los depósitos en muchos casos. Sin embargo, 6 de los yacimientos estudiados incluyen una categoría muy mal representada y que tan sólo conocemos, en este período, en contextos cultuales: los cascos. Estos aparecen, además, en todas las cronologías afectadas, desde el s. IV hasta el I a. C. y se distribuyen por toda la zona. El ejemplo de Agris es el más evidente y mejor conocido: pertenece a una serie de descubrimientos, fechados en el s. IV y en su mayoría ligados a contextos fluviales: Amfreville (hallado en el Sena en HauteNormandie), Montlaurès (procedente de una zona húmeda de Narbona, en LanguedocRoussillon) y Canosa (necrópolis del Norte de Italia) ${ }^{32}$. La tradición de los cascos ricamente decorados se perpetúa en Tintignac (v. fig. 8), con un abanico muy variado, fechado en el s. III, que abarca desde los cascos-cisne hasta los modelos con anillas. La calidad técnica, reflejada en la combinación compleja de materiales de lujo, o el empleo de técnicas depuradas como el martilleado en lámina fina son características de los cascos de este periodo. Además, la variabilidad y la originalidad de sus diseños se acentúa en esta zona en los siglos IV-III a. C.

Sin embargo, estos rasgos afectan poco a los inmensos conjuntos contemporáneos de la Galia Bélgica, formados por cantidades masivas de panoplias de calidad media en las que no tienen cabida las piezas excepcionales individualizadas por su complejidad o su decoración. Del carácter masivo de los depósitos de armas de la Galia Bélgica se ha deducido la existencia de amplios grupos de guerreros representados por las cente-

\footnotetext{
29 Bataille 2008

Bataille 2006: 249

31 Bataille, 2008: 17.
}

32 Feugère, 1994: 57 y ss. 


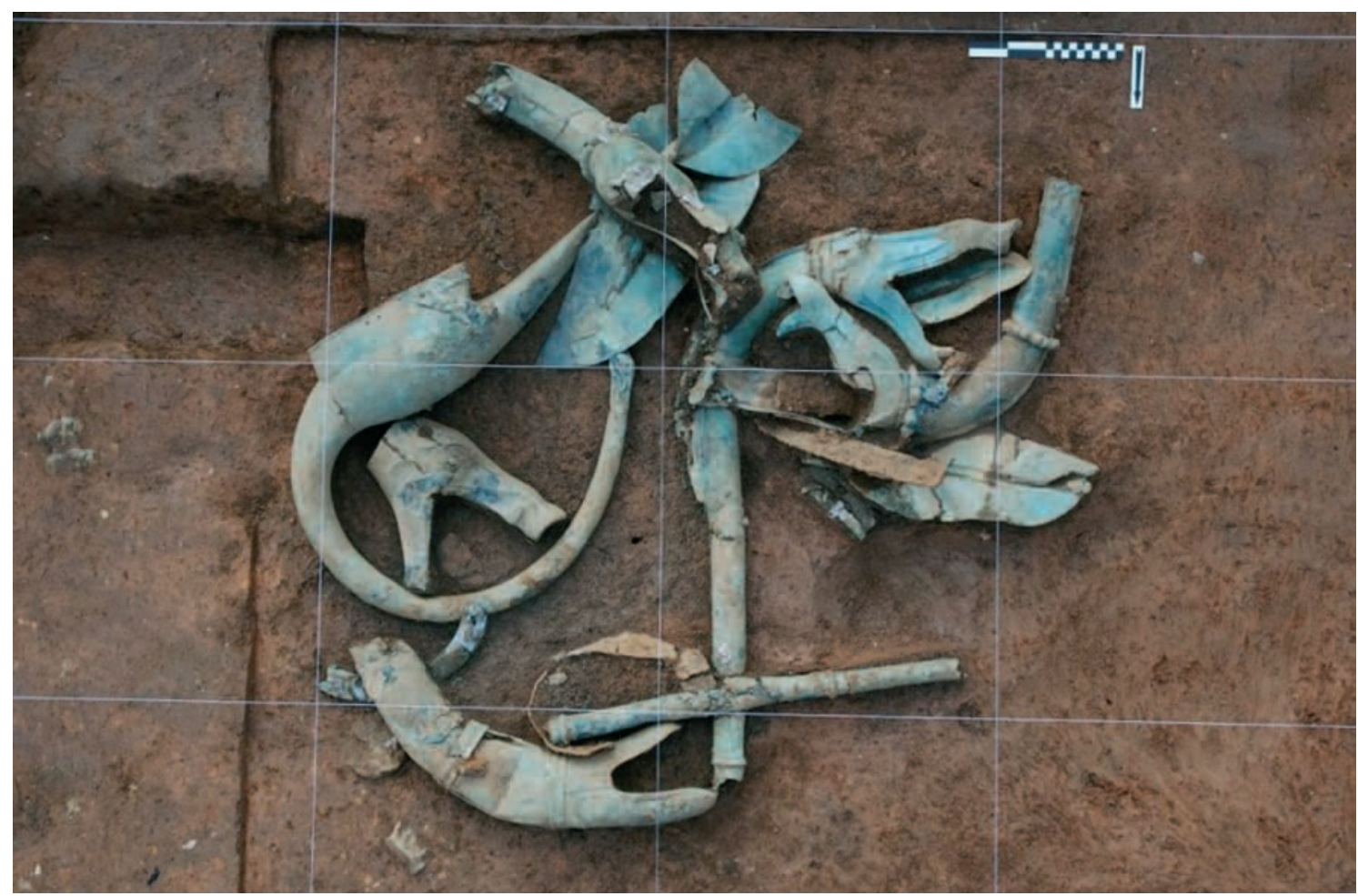

Figura 8. Fotografía del último nivel del depósito de Tintignac: a la izquierda, se aprecia el casco en forma de cisne; fragmentos de 5 carnyces. P. Ernaux/INRAP. Maniquet, 2005: 33.

nas de panoplias ofrecidas, ya fuesen las suyas propias o los despojos de sus enemigos ${ }^{33}$. Podría plantearse aquí, por el contrario, la realización de ofrendas por parte de guerreros pertenecientes a una élite restringida que estarían representados, individualmente, por sus cascos como elementos distintivos. La asociación de éstos con elementos como los arreos de caballo y la cota de malla, así como la escasez de escudos, que aparecen en cantidades muy limitadas, sugiere, de hecho, que estos guerreros fuesen principalmente jinetes, que, como recuerda Brunaux, no contarían con una mano libre para sujetar el escudo $^{34}$. La adscripción específicamente personal de los cascos decorados de esta época puede verse confirmada, además, por el hallazgo del ejemplar de Canosa en una necrópolis de tumbas individuales, y la interpretación resulta especialmente tentadora en Tintignac, cuyo depósito de armamento original está estimado en 8 espadas, 8 vainas, 9 puntas de lanza y 10 cascos, lo que corresponde prácticamente con una decena de panoplias. Esta deducción debe tomarse, sin embargo, con precaución, ya que los objetos especialmente prestigiosos pueden no haber tenido un uso funcional en el campo de batalla, y por lo tanto, no haber pertenecido a una sola persona, sino que pudieron ser objetos de culto $\mathrm{u}$ ofrendas costosas por parte de un grupo de personas (familia, clan, grupo guerrero, etc...).

Los cascos más recientes, ya pertenecientes al mundo romano, pueden entenderse de forma semejante. Se trata de ejemplares sencillos, prácticamente sin decoración y de calidad de factura muy inferior a la serie de tradición céltica, ya que eran fabricados en masa con vistas a su distribución entre los soldados romanos. Sin embargo, su hallazgo en contextos indígenas se ha atribuido a un mayor prestigio debido precisamente a su origen en la potencia itálica ${ }^{35}$. En este sentido, el fenómeno general de los militaria de época cesariana en contextos indígenas galos ha generado cierto debate recientemente. De acuerdo con la hipótesis desarrollada por A. Gorgues ${ }^{36}$, los cascos Coolus-Mannheim, por su relativa
33 Brunaux, 2004: 97.
34 Ibidem: 57.
35 Feugère, 1994: 47.

36 Gorgues, 2005 y Gorgues, 2008. 
escasez y la especificidad de sus contextos, formarían una categoría aparte dentro de este conjunto. Sugiere incluso que podrían pertenecer a un grupo de aristócratas del Sur de la Galia, que, durante el s. I a. C., los recibirían como símbolo de una alianza personal con Roma, un fenómeno reflejado en las fuentes ${ }^{37}$. Estas piezas servirían como modo de exhibición del vínculo de estos nobles con los generales romanos que los convocaban individualmente como equites aliados al margen de las tropas auxiliares locales ${ }^{38}$. A escala de toda la Galia, efectivamente, la homogeneidad de los hallazgos, correspondientes a cascos Coolus-Mannheim, así como de sus contextos, en pozos profundos o zonas fluviales $^{39}$ sugiere que se trata de una categoría de objetos particularmente apreciados, con un significado específico cuya amortización estaba reservada a contextos especiales. El precedente del uso aristocrático de los cascos anteriores a este periodo, y la manifiesta reducción del armamento en contextos rituales invitan también a apoyar la hipótesis de Gorgues.

En todo caso, la importancia de piezas de armamento defensivo dotadas de una carga simbólica especial es un rasgo significativo en los conjuntos estudiados. Si bien los escudos son objetos bien representados entre las armas galas, la presencia de un fragmento importante de cota de malla en Corent es un indicador más de la preferencia por objetos excepcionales en los depósitos del Sur de la Galia. Tan sólo otro ejemplar de esta categoría está documentado en el mundo celta, procede del depósito de BernaTiefenau, no muy alejado, al Este, del límite de nuestro estudio. Esta circunstancia podría considerarse un hecho aislado si no fuera por otro indicio del carácter selectivo de muchos depósitos de armas de esta zona: la alta proporción de piezas relacionadas con el armamento que hasta ahora se habían considerado únicas. Nos referimos a las insignias y los carnyces que han pasado de objetos rarísimos a bien conocidos en buena parte del Sur de la Galia céltica. Al mar-

37 César, III, 20 y César, la Guerra Civil, I, 39.

38 Gorgues, 2005: 87.

39 La mayor parte de los hallazgos de este tipo de cascos se han producido, en efecto, fuera de contexto, en zonas húmedas o antiguos cursos de ríos: deben citarse una pieza procedente de un brazo del Ródano cercano a Lyon, tres en la Grande gen del ejemplar procedente de Soulac-sur-Mer (Gironde, Aquitania), fuera de contexto pero incluido en la zona de estudio, todas las insignias galas proceden de yacimientos tratados en este trabajo: Corent, Mandeure y Tintignac. En cuanto a los carnyces, se concentran en estos dos últimos depósitos, pero forman una serie especialmente importante en Tintignac, donde se depositaron alrededor de 6 ejemplares.

La asociación de estos objetos con la actividad de la guerra se ve confirmada por su presencia exclusiva en depósitos de armamento, y su concentración en el área Sur de la Galia es una prueba de su especificidad regional. La calidad simbólica de las insignias, asegurada para el mundo romano ${ }^{40}$, queda confirmada por su presencia en contextos cultuales en el mundo galo, del mismo modo que la atribuida a los instrumentos musicales relacionados con la guerra. En este sentido, a pesar de no pertenecer estrictamente a la categoría de armas, puede considerarse que su fuerte vinculación con éstas, tanto práctica como religiosa, permite atribuirles un papel en los cultos guerreros. La amortización de insignias y carnyces en santuarios, por lo tanto, junto con piezas de armamento, forma parte, a nuestro parecer, del proceso de selección de un número escaso, pero cualitativamente importante, de elementos relacionados con la actividad bélica en un sentido amplio, en el que no se privilegian necesariamente las panoplias reales sino los elementos simbólicos que representan dicha actividad.

\section{APROXIMACIÓN A LA FUNCIÓN Y EL SIGNIFICA- DO DE LA PRESENCIA DE ARMAS EN LUGARES DE CULTO.}

A lo largo de los apartados anteriores, hemos demostrado la especificidad de los conjuntos de armas en contextos cultuales del Sur de la Galia. Esto no implica, sin embargo, su diferenciación radical respecto a las realidades del Norte de la Galia, ni, en ningún caso, su total homogenei-

Saône, otra en el lecho del Doubs a la altura de Ciel (Doubs), al margen de las halladas en zonas más alejadas, como la procedente del Danubio austríaco y las dos halladas en el Rin. Feugère, 1994: 40 y ss.

40 Quesada Sanz, 2007. 
dad. Por este motivo, nos proponemos ahora buscar patrones globales que caractericen, y en cierto modo, justifiquen la presencia de estos depósitos. Una pequeña reflexión semántica se impone antes de comenzar: podemos hablar de depósitos en sentido general (no estrictamente arqueológico como un conjunto cerrado de material metálico) en todos los casos tratados, ya que, si admitimos que hubo una intencionalidad detrás de la presencia de armas en los santuarios, dichos objetos debieron ser depositados. Según esta premisa, no cabe duda de que existe una íntima correlación entre la modalidad de depósito y la intención de su realización.

La característica más llamativa de los conjuntos que tratamos consiste en que, en prácticamente todos los casos, se trata de depósitos de amortización. El armamento se enterró o se depositó sobre el suelo, en el que debería permanecer por motivos rituales sin recobrar nunca su aspecto funcional. Son frecuentes las alusiones de las fuentes al carácter inamovible de las ofrendas depositadas en los santuarios galos, en particular, de aquellas que revestían un carácter guerrero $^{41}$. El rito de la destrucción de los objetos consagrados es, por otra parte, una constante en el Occidente europeo en la Antigüedad, tanto en contextos rituales como funerarios ${ }^{42}$, y se observa preferentemente en las armas. No resulta, pues, sorprendente el hecho que en la inmensa mayoría de los yacimientos comentados, el armamento apareciera sometido a diversas mutilaciones, generalmente pliegues y fracturas. En el caso de las piezas depositadas en tierra, en estructuras negativas, o sencillamente cavidades o espacios al aire libre, la destrucción voluntaria, rápida, humana, se dobla, además, de un abandono que las somete a procesos destructivos naturales (putrefacción, oxidación), lentos, que pudieron relacionarse con un "consumo" divino de las ofrendas.

La visibilidad de dichos procesos pudo constituir un factor en su utilización cultual: Determinados depósitos se realizaron en contex-

\footnotetext{
41 César, VI, 17, 3-4.

42 Aparece en los santuarios del Norte de la Galia y tumbas a lo largo de todo el periodo de La Tène, así como en la Península Ibérica.

43 Los estudios entomológicos realizados sobre los pozos aquitanos permiten afirmar que permanecieron abiertos durante un largo periodo de tiempo. Gorgues, Moret, 2003:136.
}

tos cerrados, enterrados o colocados en lugares de difícil visibilidad, pero su emplazamiento no era necesariamente desconocido. La presencia de un hogar sellando la estructura 41 de Agen, y su asociación, al igual que en Tintignac, a un pequeño edificio cuadrangular sugieren esta posibilidad. En algunos casos, la visibilidad de la estructura que albergaba la ofrenda pudo actuar como indicador de la presencia del depósito: es el caso de los fosos en los que se amontonaron, ya que no en todos ellos puede asociarse la presencia de armas a su caída tras una exposición prolongada sobre una empalizada. Una lógica similar pudo aplicarse a las cavidades naturales, o los pozos que quedaban abiertos después del sellado del depósito ritual ${ }^{43}$.

La exhibición voluntaria del armamento, en cambio, es un acto excepcional en este área: Característica de los santuarios belgas ${ }^{44}$, ampliamente documentada en las fuentes escritas ${ }^{45}$, sólo puede defenderse en dos de los yacimientos tratados en este trabajo: Corent y Le Cailar. En el caso de Corent, la composición del depósito, que incluye una espada, un escudo, una cota de malla y una insignia, recuerda las representaciones de trofeos galos, dispuestos en forma de maniquí, del arco de Orange (v. fig. 9). En este santuario, la exposición de otras categorías de materiales como despojos faunísticos, y la escasez de armas, sugieren, no obstante, que el aspecto militar constituía tan sólo una pieza de un amplio escenario ideológico. El carácter mixto del depósito de Le Cailar parece derivar de una misma voluntad de exposición a la intemperie, en un lugar especialmente representativo como es la puerta del poblado, de restos orgánicos, especialmente faunísticos, junto con un conjunto de piezas de armamento. La presencia de restos humanos, procedentes exclusivamente del cráneo, permite asociar la decapitación post-mortem y el depósito del cráneo con ritos guerreros. La muerte violenta de los individuos representados, y la hipótesis según la cual, por sus características demográficas, se trataría potencialmente

\footnotetext{
${ }^{44}$ Los hallazgos de piezas de armamento en Gournay-surAronde y Ribemont-sur-Ancre se interpretan como trofeos expuestos sobre las empalizadas, altares y edificios que forman los espacios sagrados. Brunaux 1996, Brunaux, 2004: 92-118.

45 César, VI, 17, 2-4; Plutarco, César, XXVI, 8.
} 
de un grupo de guerreros, son factores clave, que, de verse demostrados, permitirían afirmar que las armas de Le Cailar procederían del expolio de combatientes enemigos. Sin embargo, ambas posibilidades están aún en proceso de estudio.

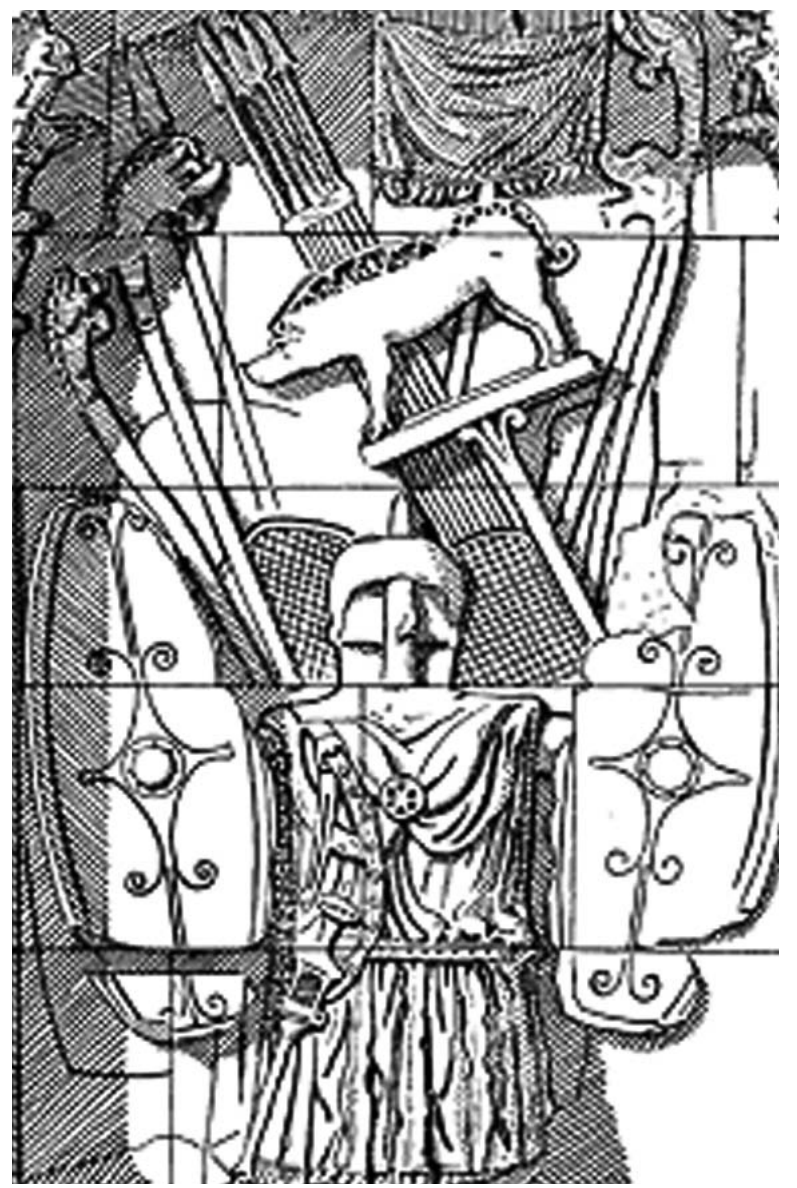

Figura 9. Trofeo galo del arco de Orange (principios del s. I d. C.). Dibujo X. Lafont. Poux, 2009.

En cualquier caso, la exposición en grandes santuarios o zonas de muralla, lugares públicos por excelencia, de piezas de armamento, ya procedan de botines o de ofrendas personales, indica el carácter cívico, dirigido a al colectivo, del rito de depósito. El modo de presentación de las armas, que aparecen bien concentradas al aire libre en una zona de paso, bien colocadas de forma reconocible como trofeos, sugiere que estos depósitos estaban destinados a la ostentación pública. La inhumación en el seno del santuario como paso posterior a la exhibición y el deterioro natural del armamento es un fenómeno reconocido tanto en los santuarios belgas ${ }^{46}$ como en Corent, ya que el trofeo se encontró en el interior de la estructura del templo. Sin embargo, la descomposición previa de las armas tan sólo puede sugerirse en Mirebeau-sur-Bèze ${ }^{47}$ y en Tintignac, donde la ausencia de anillas de suspensión o de elementos de escudo al margen de los umbos puede atribuirse también a su desmonte, como parte de la destrucción voluntaria que afecta a todas las categorías de objetos depo$\operatorname{sitados}^{48}$.

Nos encontramos, entonces, ante un rito diferente, mucho más generalizado en el Sur de la Galia, cuyo carácter restringido, quizá incluso privado, viene sugerido tanto por lo reducido o poco accesible de los espacios como por el número escaso pero la naturaleza selecta de los objetos depositados. Resulta interesante, en este sentido, el caso de Courcoury, en el que la fundación del santuario está ligada a la presencia de una tumba aristocrática, y la escasez de ofrendas sugiere un uso familiar dedicado al culto de un ancestro. Esta hipótesis se apoya en el paralelo del yacimiento de Plouër-sur-Rance (Bretaña), en la que la implantación de un lugar de culto sobre una pequeña área funeraria, también en el s. IV a. C, se asocia a las necesidades cultuales de un grupo familiar que habitaría un próspero establecimiento rural en las inmediaciones.

De este modo, la ofrenda de armas personales es la hipótesis que explica de forma más satisfactoria las peculiaridades de los depósitos de estas piezas en los lugares de culto, un rasgo que parece acentuarse a lo largo del tiempo, estando asociados, en algunos de los yacimientos más recientes, a objetos de la vida cotidiana (herramientas en los pozos del Suroeste) y a hábitats aristocráticos (Besançon) e incluyendo objetos que relacionan a sus propietarios con las élites ecuestres como los elementos de carro en Cleppé, y las espuelas y despojos de caza mayor en Besançon. En este sentido, Gabaldón afirma: "Dedicar los objetos del equipo militar y otros elementos asociados al mundo de la guerra a la divinidad podría ser una forma de afirmar la pertenencia a una elite con valores guerreros" ${ }^{49}$. Una mayor privatización y restricción de la actividad

\footnotetext{
46 Brunaux, 2004: 97.

47 Barral (Coord.), 2007: 389.
}

48 Maniquet, 2008 : 290, 292. 
bélica, o de sus símbolos, con respecto al resto de la Galia y en aumento progresivo durante la II Edad del Hierro, habría imprimido, así, un carácter particular, elitista y personal, al depósito de armas en contextos cultuales.

Sin embargo, la utilización de las armas en el desarrollo del culto no puede descartarse: insignias, carnyces, despojos de banquetes y armas profusamente decoradas evocan una alta codificación de los depósitos. La potencialidad escenificadora de estos objetos permite sugerir la posibilidad de la celebración, en algunos santuarios, de ceremonias en las que combates agónicos, desfiles militares y otras competiciones armadas pudieron jugar un importante papel, tal y como atestigua la documentación para el mundo griego ${ }^{50}$.

\section{III. ¿SANTUARIOS BELGAS, CELTAS, Y AQUITANOS?}

\section{Tipos De Santuarios: ¿"Belgas"?}

La definición de los santuarios galos de acuerdo con el paradigma de los yacimientos de la Galia Bélgica pasa por una contradicción fundamental: se trata de un modelo regional, ligado a la organización social y las prácticas cultuales de un pueblo en particular, los Belgas ${ }^{51}$, y sin embargo, sería representativo del conjunto de la Galia, un gran mosaico de pueblos y tradiciones materiales. La confusión nace de la caracterización arqueológica de los santuarios belgas, que ha sido definida por la combinación de una serie de rasgos:

- La delimitación del espacio sagrado mediante fosos en los que se depositan ofrendas y que pueden reforzarse mediante empalizadas. A excepción de los pozos y los hallazgos en cavidades naturales, se trata, en realidad, de una herramienta común, en los santuarios galos, para delimitar el temenos y dividirlo en diferentes áreas. En algunos santuarios, como Cleppé, Courcoury o Muron, las armas se concentran especialmente en la red de fosos que rodea y recorre el santuario, por lo que puede considerarse que las ofrendas de piezas de armamento en estas estructuras son una práctica habitual en el marco de los cultos guerreros galos. Sin embargo, la representatividad de los fosos como indicadores de un contexto cultual, que hasta ahora se había considerado segura, está siendo cuestionada ${ }^{52}$. La frecuencia de los fosos como delimitadores del espacio en el mundo galo ha provocado la sobreinterpretación ritual de numerosos yacimientos de tipo "enclos" (recinto), como los famosos Viereckschanzen, o incluso de pequeños establecimientos, o de parcelas delimitadas.

- La presencia de fosas de ofrendas, altares y "altares huecos". La frecuencia de los depósitos de armamento en las fosas de los santuarios galos queda confirmada por los hallazgos de Mirebeau-sur-Bèze, Tintignac, Mandeure y Corent, yacimientos que se caracterizan, además, por una especial riqueza en sus conjuntos de armas. Del mismo modo, el altar de basalto de Corent basta para constatar la existencia de este fenómeno, en realidad raro en los santuarios de la Galia Bélgica ${ }^{53}$, en el Sur del territorio galo. En cuanto a los altares huecos, se trata en realidad de pozos de ofrendas que se llenaron progresivamente. Las fosas de libación del santuario de Corent, que Poux ha identificado en otros yacimientos galos ${ }^{54}$, e incluso los pozos del Suroeste, pueden clasificarse dentro de esta categoría, realmente muy poco definida, de estructuras cultuales.

- La abundancia de ofrendas, en particular de armamento, faunísticas, y, en menor medida, de restos humanos. La concentración de estas tres categorías, así como su localización, esparcidas cerca de la muralla de Le Cailar, permiten atribuir a este yacimiento un aspecto "belga" en el extremo Sur de la Galia. En menor medida, el santuario de Corent se caracteriza por la exhibición de sus numerosos despojos faunísticos, y, tan sólo recientemente, ha proporcionado un trofeo de armas galas.

\footnotetext{
${ }^{50}$ Pausanias, V, 12,8.

51 Sobre la particularidad de los pueblos belgas ese fundan Brunaux, 2006 y Roymans, 1990.

52 Brunaux et alii, 2000.
}

53 Sólo Ribemont-sur-Ancre puede interpretarse así. 54 Poux, 2004: 319. 
En definitiva, pocos aspectos diferencian el santuario de Corent, separado sin embargo por más de 100 años de los yacimientos paradigmáticos, o la zona cultual de Le Cailar, distante cientos de kilómetros, de los santuarios belgas. Es más, algunos de éstos, los menos ricos en armas, como Montmartin (Oise), sólo diferen de los de Muron o Mirebeau-sur-Bèze desde un punto de vista cuantitativo. Esta proximidad se debe a que, en realidad, los llamados "santuarios belgas" se caracterizan por rasgos muy generales, que se encuentran combinados en un grupo amplio de yacimientos, dentro y fuera de la Galia Bélgica, mientras que esta apelación, regional, se aplica a santuarios cuyos depósitos de armas no son excepcionales respecto al resto de la Galia, como Fesques. En este yacimiento, los conjuntos de armas, relativamente numerosos, aparecen ofrecidos en fosos y fosas, un perfil que se repite en la mayoría de los santuarios incluidos en este estudio.

Por el contrario, existe un grupo de lugares de culto, entre los que se encuentran Gournay y Ribemont, pero también Le Cailar y, en menor medida, quizá Corent, en los que las armas, los restos humanos y los despojos faunísticos tienen un estatus privilegiado, no tanto por su cantidad, sino por su tratamiento: su exposición como manifestación colectiva de culto. La diferencia entre el depósito de armas en un tipo de santuario u otro radica, pues, más en la escala de integración de los ritos que en la localización geográfica, puesto que este fenómeno se produjo simultáneamente en diferentes puntos de la Galia. Son la manifestación de un proceso de generalización de los ritos guerreros que debió incrementar su papel cohesionador, en el s. III. Brunaux afirma que "la ofrenda [en Gournay] no es un monumento privado, representa a una sociedad" ${ }^{\prime 5}$. Los yacimientos que responden en menor medida al esquema enunciado, como Corent y Fesques, tienen una cronología inmediatamente posterior al abandono de los principales santuarios guerreros. Representarían los últimos coletazos de ese proceso, donde las armas comenzarían a ser un factor residual respecto a otros tipos de ofrendas. Montmartin, el santuario que sustituye, a escala local, a
Gournay, marca el final del culto guerrero masivo: éste se enmarca ya en una residencia aristocrática. Otros santuarios de La Tène B y C1 nunca habrían acogido ritos colectivos, y en algunos, como la grotte des Perrats o Courcoury, habría ya dado comienzo otro fenómeno llamado a tener un gran éxito en La Tène D.

\section{El PROBLEMA DEL CONTEXTO RITUAL: LOS POZOS "AQUITANOS".}

Los pozos localizados en el Suroeste de la Galia plantean graves problemas de interpretación, de modo que merece la pena explicar el porqué de su importancia en este trabajo. La historiografía les ha atribuido funciones muy diferentes, en especial recientemente, ya que, desde que se conocen hasta los años 1970 se consideraron como estructuras funerarias debido al hallazgo, en algunos de ellos, de restos humanos tanto inhumados como cremados. Fueron necesarios 20 años par que las investigaciones de Boudet en Agen $^{56}$ y de Vidal en VieilleToulouse $^{57}$ desterraran esta interpretación, constatando que sólo un 30\% de los pozos contenían restos humanos aislados y escasos ${ }^{58}$. El carácter homogéneo y particular de estas estructuras, generalmente cuadradas, de profundidad variable y, en muchos casos, dotadas de recubrimientos de madera, así como los hallazgos de objetos de prestigio en su interior, han favorecido su interpretación ritual.

La naturaleza del rito relacionado con los pozos no ha sido, sin embargo, objeto de un consenso entre los investigadores: a día de hoy, se opone una posición, generalmente aceptada aunque poco firmemente defendida, que supone su empleo como vía de comunicación con divinidades de carácter ctónico, frente a una interpretación más pragmática, que apunta a ofrendas de fundación de pozos para favorecer su prosperidad $^{59}$. Esta tesis implica, de hecho, que los pozos carecerían, en origen, de una función cultual, para sustituirla por un empleo práctico para la extracción de agua. Otra tendencia actual, en suma, es la adopción de una posición poco comprometedora según la cual la heterogeneidad de los pozos del

\footnotetext{
55 Brunaux, 2004: 98.

56 Boudet, 1996.

57 Arramond, Requi, Vidal, 2007: 385
}

58 Ibidem.
59 Gómez de Soto, Milcent et alii, 2003:134 y ss. 
Suroeste impediría cualquier interpretación de su función ${ }^{60}$. Sin embargo, la existencia de una categoría de estructuras semejantes parece evidente, teniendo en cuenta su relativa uniformidad morfológica (los pozos circulares son muy infrecuentes y las profundidades y dimensiones permanecen similares), espacial y cronológica (s. I a. C.).

El contexto en el que se enmarcan los pozos no contribuye en modo alguno a solucionar el debate, ya que su concentración en zonas urbanas, en un área restringida que abarca tan sólo el corazón de la Aquitania, los convierte en un fenómeno regional pero a la vez selectivo. Su distribución, además, es relativamente dispersa y no permite encuadrar los pozos en ninguna estructura cultual de época gala o romana. Del mismo modo, no se observa ninguna preferencia topográfica, ni respecto al emplazamiento en el interior de la trama urbana, ya que se encuentran tanto en pleno oppidum como en los márgenes de las áreas de ocupación. Sin embargo, el relleno de los ejemplos estudiados aquí responde, por lo general, a un esquema fijo (v. fig. 10): las capas superiores, poco organizadas, presentan un aspecto de abandono al aire libre. Separados de éstas por un cierre de cantos de río y/o de fragmentos de ánforas, en capas ricas en materia orgánica, se encuentran los depósitos organizados que contienen el material arqueológico, incluyendo, en ocasiones, capas completas repletas de fragmentos anfóricos. Cercanas a la base de la estructura, las ofrendas están constituidas, por lo general, de una amplia variedad de objetos cerámicos y metálicos, en los que predominan las ánforas, la cerámica local y los recipientes metálicos. En efecto, las piezas de armamento son, como bien recuerda Gorgues ${ }^{61}$, un fenómeno aislado dentro de los pozos aquitanos, pero forman parte de la clave del problema de su interpretación.

Los cascos Coolus-Mannheim son prácticamente la única categoría de armas que se encuentra en estos contextos, con una excepción notable: el casco de Vic Fezensac, de tipo céltico tardío occidental, un modelo muy simplificado, con reborde $^{62}$. Ambos tipos son contemporáneos, pero presentan problemas de datación precisa, debido a la escasez de hallazgos en contexto. En ambos casos, sin embargo, la mayoría de los ejemplares se vinculan a zonas fluviales (los hallazgos más abundantes de Coolus-Mannheim provienen de la Saône), o zonas de difícil interpretación de oppida importantes (Agen, Vieille-Toulouse, Alesia, Berna), una distribución reducida y desigual. La homogeneidad de su uso en los pozos, no obstante, está garantizada por su colocación voluntaria siempre en posición invertida y en depósitos organizados al fondo de las estructuras, por lo que constituye un buen punto de partida para el análisis de su función.

A día de hoy, resulta difícil negar el carácter intencional $^{63}$ de los depósitos de los pozos de Agen y de los XVI y XXIII de Vieille-Toulouse. La hipótesis según la cual cascos, sítulas, ánforas, cerámicas de mesa, cubos decorados y hoces completas procedentes de depósitos superiores serían material de deshecho o habrían caído accidentalmente en los pozos no justifica su organización, que revela un trabajo de colocación de los objetos $^{64}$. Menos obvio es el hecho de que los pozos fueran excavados expresamente con el objetivo de albergar dichas ofrendas, puesto que pudieron tener una vida útil previa al depósito, y sufrieron un proceso posterior de colmatación. El carácter reducido de la estructura y la escasa calidad del sistema de captación de agua podrían indicar su carácter doméstico ${ }^{65}$.

En la mayoría de los casos que nos ocupan, el sellado sistemático de las capas ricas en material arqueológico permite separar el área del depósito del tramo del pozo que permaneció abierto, garantizando así su protección. La permanencia de la estructura abierta al aire libre, de todos modos, no resulta especialmente problemática respecto a su interpretación ritual, teniendo en cuenta que los llamados "altares huecos" o "fosas de libación" repletos de ofrendas faunísticas y restos humanos en Ribemont-sur-Ancre y de ánforas vinarias en Corent tampoco fueron cerrados tras su utilización ritual. Es más, la presencia de ofrendas en los fosos de Muron, Mirebeau-sur-Bèze, Courcoury, Cleppé y de la inmensa mayoría de los santuarios galos, aún habiendo sufrido un proceso de colmatación totalmente natural tras el depósito, nunca ha sido objeto de debate alguno.

\footnotetext{
60 Arramond, Requi, Vidal, 2007: 387

61 Gorgues, 2005: 85.

62 Feugère, 1994:66.
}

63 Requi, Benquet, 2009: 430.
64 Ibidem.
65 Ibídem: 433. 


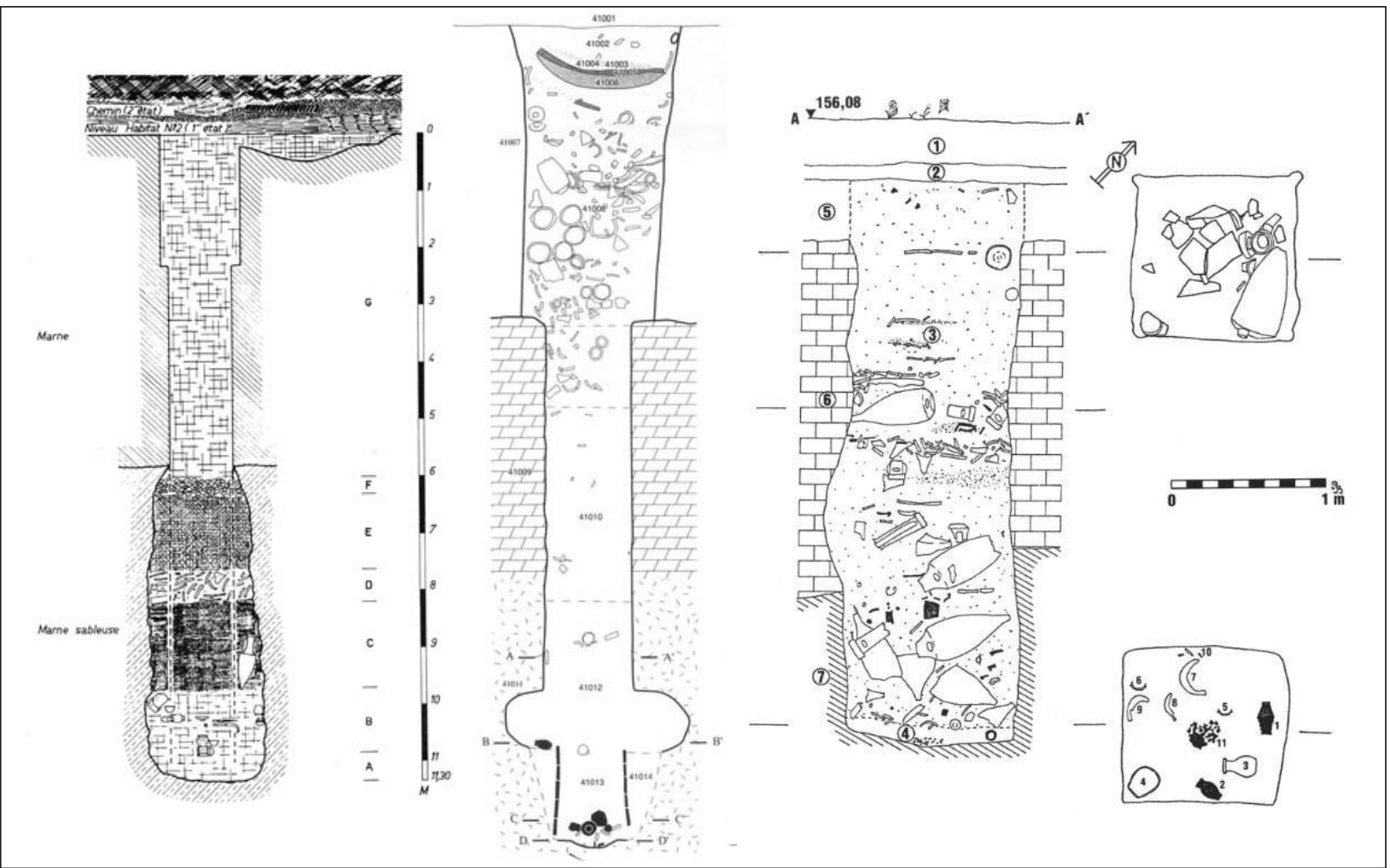

Figura 10. Cortes estratigráficos de los pozos XVI de Vieille-Toulouse (Gorgues, 2005:91) y st. 41 y Z1 de Agen (Verdin, Bardot, 2007:231).

Esto se debe a que, hasta ahora, se ha obviado toda comparación de los pozos con otras clases de estructuras que pudieran presentar semejanzas con ellos, favoreciendo una interpretación regional que los considera como un fenómeno aislado. Sin embargo, es posible enmarcar los pozos del Suroeste en una serie de estructuras negativas, en ocasiones naturales, dedicadas a las ofrendas pero en uso permanente, conocidas en el resto de la Galia: en este sentido, llama la atención el parecido entre la asociación utillaje-vajilla de metalarmas-cerámica tardía en los pozos, y en una proporción mucho mayor, en la falla de Larina.

La relación de los pozos, que no siempre alcanzan la capa freática, con el agua, un

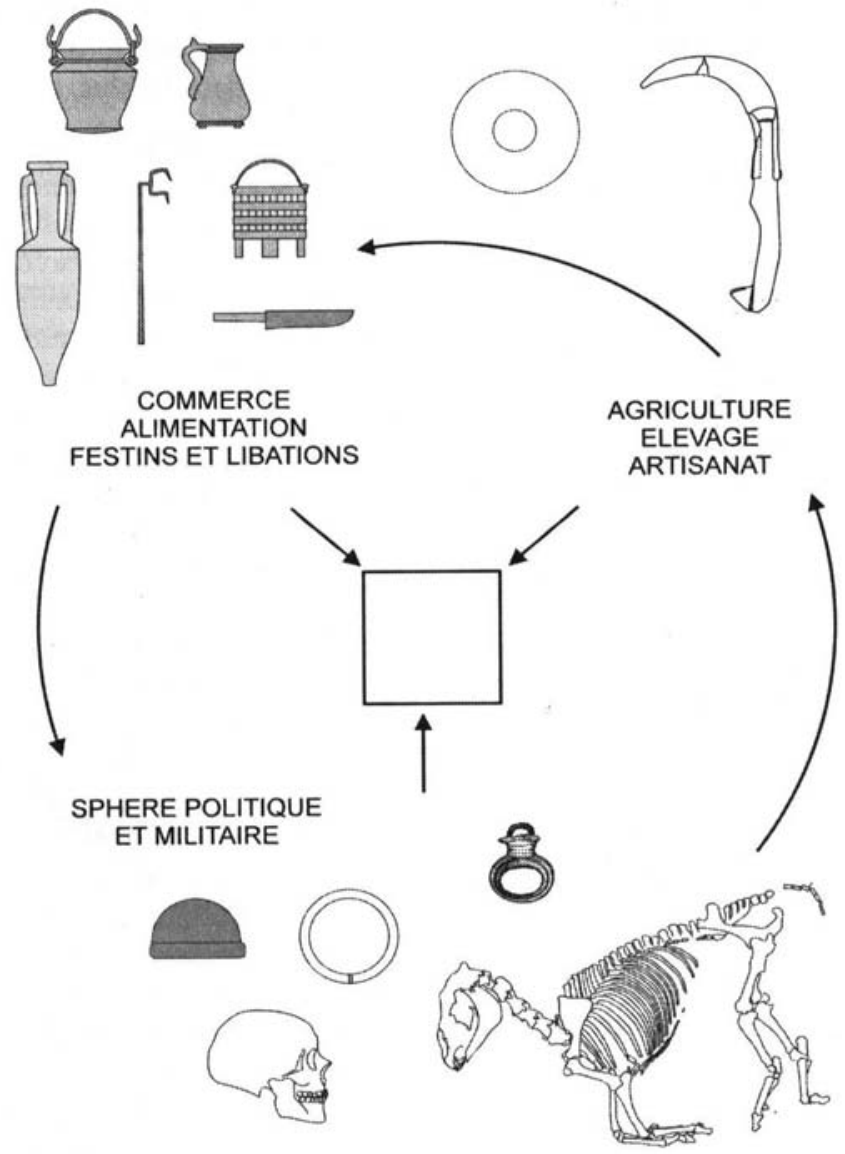

Figura 11. Categorías de material halladas en los pozos aquitanos Poux, 2004: 322 
rasgo que tanto debate ha suscitado ${ }^{66}$, acaso pudiera considerarse como la causa primaria de su excavación ${ }^{67}$. El carácter acuático de estas estructuras cuenta con un paralelo en la frecuencia de los hallazgos de cascos CoolusMannheim, y en menor medida, de modelos célticos tardíos, en contexto fluvial ${ }^{68}$, una tradición ritual que se remonta a la Edad del Bronce en toda la Europa templada. Las famosas alusiones de las fuentes a tesoros ofrecidos en lagos sagrados tolosanos ${ }^{69}$, aunque referentes a masas y objetos de metal precioso, confirman la importancia de la práctica de ofrenda de objetos metálicos a las aguas, aún en períodos muy recientes, en el Suroeste de la Galia. Por otro lado, la asociación de recipientes cerámicos destinados a contener líquidos (formas altas, vajilla y contenedores vinarios), cubos y sítulas, junto con la posición de los cascos y la reutilización manifiesta del ejemplar de Vic Fezensac permite incluso sugerir un empleo de estas piezas como recipientes destinados a contener líquidos o realizar libaciones. Sin embargo, este uso no implicaría, a nuestro entender, la "desmilitarización" de los cascos, como sugiere Feugère ${ }^{70}$, sino que, como Poux ${ }^{71}$, consideramos que expresaría la convergencia de tres signos de prestigio (v. fig. 11): el control de las armas y el privilegio de realizar ofrendas alimenticias y consumir vino. En esta cronología, sin embargo, parece que la escasez y la reutilización de las armas tienen su explicación en la competencia en la que convivían, de forma ya residual, con otras ofrendas.

\section{Armas, Vino Y BANQUETE EN LOS SANTUA- RIOS.}

El reconocimiento del papel de los ritos de banquete en la Edad del Hierro gala ha sido una conquista conjunta de la arqueología ${ }^{72}$, el estudio de las fuentes ${ }^{73}$ y la aportación de la antropología $^{74}$. En particular, M. Poux ha demostrado la magnitud del fenómeno del consumo del vino en la Galia de los últimos siglos antes de nuestra era. En el ámbito ritual, Poux menciona como indicio arqueológico fundamental la presencia de ánforas vinarias tratadas como ofrendas o como objetos relacionados con el culto. 8 de los 14 yacimientos incluidos en nuestro estudio coinciden con esta observación: en el santuario de Corent, estudiado por el propio Poux, se excavó una gran cantidad de ánforas vinarias aún llenas que habían sido objeto de "decapitaciones": se trata de fracturas violentas de la parte superior del ánfora mediante un instrumento cortante, que se asocian al carácter antropomorfo de los recipientes y al rito de la decapitación postmortem. Los fragmentos resultantes se ofrecieron en pozos o fosas, e incluso determinadas zonas del santuario se pavimentaron con fragmentos de ánforas, como el entorno de la fosa de libaciones frente a la entrada del recinto (v. apartado I. 6.).

La práctica de la fractura intencional y el depósito de las ánforas en estructuras negativas se han documentado claramente en Mirebeausur-Bèze, Muron, Cleppé y Besançon ${ }^{75}$, y parecen ser fenómenos especialmente frecuentes en el Sur de la Galia céltica ${ }^{76}$. En Le Cailar, las ánforas vinarias masaliotas constituyen prácticamente la única categoría cerámica presente en el depósito, y con frecuencia grandes fragmentos aparecen posados horizontalmente, aunque por el momento no se han definido zonas pavimentadas. El papel de las ánforas vinarias en los pozos del Suroeste, actuando como sello del depósito en ocasiones, y prácticamente omnipresentes en ejemplares completos en el relleno, así como el carácter abierto de los pozos, sugieren una similitud con las "fosas de libaciones" o "fosas de ánforas" del Centro-Este de la Galia". La importante representación, además, de otros objetos relacionados con el consumo de vino, como la vajilla campaniense, los vasos balustres, las sítulas, cubos decorados y oinocoes, confirman la relación entre la práctica del depósito de ofrendas de armas en pozos y el uso ritual de esta bebida. La vajilla metálica representa tam-

\footnotetext{
66 Gómez de Soto, Milcent et alii, 2003:134, Arramond, Requi, Vidal, 2007.

67 Requi, Benquet, 2009: 433.

68 Feugère, 1994: 47 y 72.

69 Estrabón, IV, 1, 13.

70 Feugere, 1994: 72.

71 Poux, 2004: 319.
}

\footnotetext{
72 Poux, 2004.

73 Brunaux, 2002.

74 Dietler, 1996.

75 Poux 2004: 84, 86, 105.

76 Poux, 2004: 320.

77 Poux, 2004: 324
} 
bién una parte esencial del depósito de Larina, en Corent y en Cleppé y las ofrendas cerámicas relacionadas con el consumo del vino son especialmente numerosas en Besançon, Mireabeausur-Bèze y Muron, donde aparecen en asociación directa con los depósitos de armas.

La ingesta de alimentos, en particular de carne, durante el banquete es la característica específica de la modalidad gala de esta celebración: testimonio de esta práctica es la abundancia de restos de fauna consumida en Corent, Le Cailar, Besançon (piezas de caza, en particular jabalí), Muron y Mirebeau-sur-Bèze. Los instrumentos relacionados con el despiece, la preparación y el consumo de carne aparecen, aunque menos representados, en Le Cailar (un cuchillo y un rallador), Larina (grills, tenedores y cuchillos), Corent (cuchillos y calderos), Tintignac (caldero) y Agen (cuchillo). Para explicar esta escasez de instrumentos, puede invocarse el que las actividades de sacrificio y distribución de carne estuviesen reservadas a un número limitado de individuos, circunstancia que se ha sugerido para otros contextos de banquete ${ }^{78}$, y que concuerdan con las tesis actuales sobre el sacerdocio en la Galia céltica ${ }^{79}$. Los pozos aquitanos incluyen con frecuencia, además de restos de fauna, elementos relacionados con la producción alimenticia como hoces y muelas.

La asociación sistemáticamente entre estas ceremonias y la guerra en el Sur de la Galia, si bien está demostrada por la arqueología, mediante los indicios evocados, se ve fuertemente apoyada por las fuentes históricas. La descripción del banquete galo de Posidonio ${ }^{80}$, el texto más completo sobre la materia, afirma el carácter militar de los asistentes, así como el desarrollo del banquete en función de códigos jerárquicos ligados a la clientela personal de aristócratas guerreros. La semejanza entre el banquete y la asamblea de guerreros, así como la alusión a combates agónicos en el transcurso del mismo $^{81}$, resaltan su relación con cultos guerreros. El texto de Posidonio pone de relieve, igual-

\footnotetext{
78 Berrocal, 1994.

79 Brunaux, 2004: 143.

80 Conservado en Ateneo, Deip, IV, 151-154.

81 Ateneo, Deip, IV, 154

82 Dietler, 1996: 92 y ss.
}

mente, el carácter personal de la participación en el banquete, y su papel vinculante en el marco del sistema de clientela militar, aspectos que lo relacionan con lo que ya sabemos sobre la función cohesionadora de los banquetes en las sociedades preindustriales ${ }^{82}$. En este sentido, resulta interesante señalar la mención de César de relaciones clientelares personales muy poderosas, próximas a la devotio hispana, en la Aquitania protohistórica $^{83}$, lo que invita a prestar especial credibilidad a este pasaje en su aplicación al Sur de la Galia.

El dato converge, además, con la reducción y el carácter simbólico del equipamiento militar que hemos constatado en los santuarios, en los que la realización de ofrendas de armas parece limitada a un pequeño grupo de aristócratas. La pervivencia del matiz militar hasta momentos muy cercanos a la conquista romana parece ser un rasgo propio de la Aquitania, que se refleja en las fechas tardías de los pozos. La convivencia de las tres "esferas" de prestigio, el armamento, el vino y el banquete, y la producción agrícola, refleja, en realidad, una drástica reducción de la ofrenda de armas en favor de otras prácticas rituales. Del mismo modo, la politización del banquete público, antaño militar, se ve reflejada el ejemplo del noble arverno Luern ${ }^{84}$, que invitaba a todo aquel que pasara, llevara o no armas, como parte de su campaña y de su demostración de riqueza. Probablemente, este fenómeno es el responsable de los últimos banquetes de Corent $^{85}$, que sustituían ya, definitivamente, el factor cohesionador de los ritos guerreros del s. III.

\section{CONCLUSIONES}

En un principio, la delimitación de nuestro estudio podía parecer arbitraria, en la medida en que se basaba en un aspecto negativo de la historiografía actual. El conjunto de yacimientos, además, se ha revelado heterogéneo, ya que abarca varios patrones de depósito de armas en

83 César, III, 22. En este pasaje, César menciona al noble aquitano Adiatuanos, cuyos guerreros clientes estaban obligados a morir con él en combate o, de lo contrario, a suicidarse tras la muerte de su jefe.

84 Ateneo, Deip, IV, 152.

85 Poux, 2008: 181. 
los santuarios. Sin embargo, el territorio analizado ha resultado útil para completar y tomar distancia respecto al estudio de este fenómeno en la Segunda Edad del Hierro gala. El estudio conjunto de estos 14 yacimientos ha permitido cuestionar la óptica regional que rige la interpretación los santuarios de la Galia Bélgica y los pozos del Suroeste, demostrando a la vez que su variabilidad, tanto geográfica como cronológica, no impide establecer patrones inteligibles de depósito de armas en los santuarios galos.

El análisis de los depósitos de armas en sí mismos, en función de su cronología, su composición y sus parámetros cuantitativos, pone de manifiesto la importancia del criterio de calidad, tanto técnica como simbólica, que apunta a una selección estricta de las armas depositadas en algunos yacimientos. Esta exigencia se refleja en la frecuencia del depósito personal, reducido, por parte de las élites, de piezas de armamento acompañadas de objetos simbólicos que representan la actividad bélica, así como otros signos de estatus. La oposición entre los depósitos relacionados con el ámbito privado, y aquellos que se exhiben antes lo ojos de la colectividad contribuye a distinguir dos niveles de integración o de restricción del acto ritual, lo que puede reflejar una estructura social más o menos aristocrática.

De este modo, proponemos sustituir el concepto de santuario belga por santuario guerrero colectivo, en contraposición a una tendencia a la privatización del acto ritual por parte de las élites. En este sentido, dos factores sociales entran en juego: el control del culto y el monopolio de la posesión de armas, elementos difíciles de disociar en el registro arqueológico de los santuarios. Todo apunta a la tendencia generalizada en el Sur de la Galia a restringir el papel de la actividad bélica dentro de un conjunto de prácticas de prestigio, principalmente el banquete, revestidas de una función social de cohesión y ostentación pero que afectarían a proporciones variables de la sociedad. Así, el éxito de la representación simbólica de la guerra habría corrido paralelo no sólo a la evolución de la organización de la actividad bélica sino también a la de la aristocracia gala, que perdería gran parte de su matiz guerrero a partir del s. III en favor de un modelo de riqueza y poder político. $\mathrm{Si}$, como cree Brunaux ${ }^{86}$, la ofrenda colectiva de armas legitimaría ritualmente el derecho a verter sangre humana para el guerrero, poco a poco el vertido de sangre animal y de vino, sangre vegetal, acapararía el vocabulario legitimador de las elites.

\section{Bibliografía}

Arcelin, P., Brunaux, J. L. (Dir.) (2003): « Cultes et sanctuaires en France à l'Âge du Fer. » Dossier Gallia 60, pp. 1-268.

Arramond J.-C., Requi C., Vidal M. (2007) : "Les recherches anciennes et les fouilles en cours sur les sites de Vieille-Toulouse, Toulouse-Estarac et Toulouse Saint-Roch, aux IIe et Ier siècle av.J.-C." en Izac-Imbert, L. (Dir.), 2007, pp. 385-409.

Barral, P. et alii (2003): «La France du Centre-Est (Auvergne, Bourgogne, Franché-Comté, RhôneAlpes)». En Arcelin y Brunaux (dirs.), 2003, pp. 139-168.

Barral, Ph., Joly, M. (2003): «Le sanctuaire de Mirebeau-sur-Bèze : reflet des soubresauts du monde celtique. » Archéologia 401, pp. 32-41.

Barral, Ph. (Coord.) (2007) : «Epomanduodurum, une ville chez les séquanes : Bilan de quatre années de recherche à Mandeure et Mathay (Doubs) » Gallia 64, pp. 353-434.

Bataille, G. y Guillaumet, J.-P. (2006) : Les dépôts métalliques au second âge du Fer en Europe tempérée. Actes de la table ronde de Bibracte, 13-14 octobre 2004.

Bataille, G. (2006) : " Dépôts de mobiliers métalliques de la période de La Tène. Premiers essais de classement. » en Bataille y Guillaumet, 2006, pp. 247-256.

Bataille, G. (2008) : Les Celtes : des mobiliers aux cultes. Université de Dijon.

Berrocal Rangel, L. (1994) : El altar prerromano del Castrejón de Capote. Ensayo etno-arqueológico de un ritual céltico en el Suroeste peninsular. UAM. Madrid.

Boudet, R. (1996) : Rituels Celtes d'Aquitaine. Éds. Errance, Paris.

Brunaux, J.-L., Lambot, B. (1987) : Guerre et armement chez les Gaulois : 450-52 av. J.-C. Coll. Hespérides, éds. Errance, Paris. 
Brunaux, J.-L., Méniel, P. (1983): « Le sanctuaire de Gournay-sur-Aronde (Oise) : structures et rites, les animaux du sacrifice » Revue Archéologique de Picardie, 1, pp. 165-173.

Brunaux, J. L., Méniel, P., Rapin, A. (1980) : «Un sanctuaire gaulois à Gournay-sur-Aronde (Oise).» Gallia 38, 1, pp. 1-25.

Brunaux, J. L., Méniel, P., Poplin, F. (1985): Gournay I. Les fouilles sur le sanctuaire et l'oppidum. Revue archéologique de Picardie, numéro spécial.

Brunaux, J. L. (Dir.) (1991) : Les sanctuaires celtiques et leur rapport avec le monde méditerranéen. Colloque international à Saint-Riquier, 8 octobre 1990. Paris.

Brunaux, J. L. (Dir.) (1991) : « La chronologie du second Age du Fer en Gaule du Nord. Table ronde, Ribemont-sur-Ancre. » Revue Archéologique de Picardie 3-4, pp. 5-242.

Brunaux, J. L. (1996): Les religions gauloises. Rituels celtiques de la Gaule indépendante. Eds. Errance. Paris.

Brunaux, J.-L. (2002) : «Les Guerriers à la table des dieux : les fragments de Poseidonios dans les Deipnosophistes d'Athénée : quelles manières de table pour les Gaulois ? » in Repas des vivants, nourriture pour les morts. Actes du XXVe colloque de l'A.F.E.A.F., Charleville Mézières, 2001. Supplément au Bulletin de la Société Archéologique Champenoise $\mathrm{n}^{\mathrm{o}} 1$, pp. 273-282.

Brunaux, J. L. (2004): Guerre et religion en Gaule. Essai d'anthropologie celtique. Eds. Errance. París.

Brunaux, J.-L., et alii (2000) : " Actes de la table ronde sur les enclos celtiques, Ribemont-surAncre, 5 et 6 septembre 1999. » Revue Archéologique de Picardie, $\mathrm{n}^{\circ}$ spécial 1-2.

Dietler, M. 1996: "Feast and Commensal Politics in the Political Economic: Food, Power and Status in Prehistory Europe". En P. Wiessener y W. Schiefenhövel (eds.): Food and the Status Quest. Berghahn Books, pp. 87- 125.

Duval, A., Morel, J.-P., Roman, Y. (dirs.) (1990) : Gaule interne et Gaule méditerranéenne aux IIème et Ier siècles avant J.-C. Confrontations chronologiques. Actes de la Table Ronde de Valbonne (11-13 Novembre 1986). Revue Archéologique de Narbonnaise, Supplément 21.
Feugère, M. (1994): Casques antiques. Les Visages de la guerre de Mycènes à L'Antiquite tardive. Ed Errance, Paris.

Gabaldón Martínez, M. M. (2004): Ritos de armas en la Edad del Hierro. Armamento y lugares de culto en el antiguo Mediterráneo y el mundo celta. Anejos de Gladius, 7. Madrid.

Gómez de Soto, J., Lejars, T. (1991): « Sanctuaires préromains en extrême Occident » in Brunaux, J. L. (Dir.), 1991, pp. 126-132.

Gómez de Soto, J., Milcent, P. Y. et alii (2003): «La France du Centre aux Pyrénées (Aquitaine, Centre, Limousin, Midi-Pyrénées, PoitouCharentes)». Arcelin y Brunaux (dir.), 2003, pp. 107-138.

Gorgues, A. (2005) : « Les casques CoolusMannheim de Vieille-Toulouse. Remarques sur les transferts d'armements à l'époque républicaine dans les provinces occidentales. ” Gladius XXV, pp. 83-94.

Gorgues, A. (2008) : « Militaria d'époque césarienne à Boé (Lot-et-Garonne) et à Toulouse (HauteGaronne). Quelques considérations. » en Poux, M. (Dir.), 2008, pp. 251-264.

Izac-Imbert, L. (Dir.), (2007) : Les Âges du Fer dans le Sud-Ouest de la France. XXIVème colloque de l'AFEAF à Toulouse, 20-23 Mai 2004. Supplément Aquitania, 14/1.

Joly, M., Duperé, B., Logereau, S. (2009): "Mirebeau-surBèze. Côted'Or." (en linea) Disponible en web: http:/www.mirebeau.archeophile.com/index.htm. Consultado: 6 de diciembre de 2010.

Lejars, T. (1996): «Les armes en fer : une source d'information privilégiée pour l'étude du fonctionnement des sanctuaires celtiques ». Mélanges de l'Ecole française de Rome, Antiquité 108, 2, pp. 505-522.

Maniquet, C. (2008) : « Le dépôt cultuel du sanctuaire gaulois de Tintignac ». Gallia 65, pp. 273-326.

Moret, P. (2008) : « Tolosa, 106 - 47 av. J. C. : topographie et histoire. » Pallas 76, pp. 295329.

Pailler, J.-M. (dir.) : Tolosa. Nouvelles recherches sur Toulouse et son territoire dans l'Antiquité. Ecole française de Rome.

Perrin, F. (1991) : « Le site de La Chuire (Camp de Larina, Hyères-sur-Amby, Isère) et l'Isle Crémieu à l'âge du Fer. » en Duval, A. (dir.): 
Les Alpes à l'âge du Fer. Actes du Xème colloque de l'AFEAF à Yonne-Chambéry. Supplément de la Revue Archéologique de Narbonnaise, 22, pp. 21-47.

Perrin, F. (1990) : Un dépot d'objets gaulois à Larina : Hières-sur-Amby, Isère. Lyon : Circonscription des antiquités historiques.

Poux, M. (2000) : « Espaces votifs - espaces festifs. Banquets et rites de libation en contexte de sanctuaires et d'enclos. » Revue Archéologique de Picardie, 1, pp. 217-231.

Poux, M. (2004) : L'Age du vin. Rites de boisson, festins et libations en Gaule indépendante. Série Protohistoire, Eds. Monique Mergoil, Paris.

Poux, M. (2009): « Corent: découverte d'un exceptionnel trophée gaulois» Comunicado de prensa, Clermont-Ferrand, 12/10/09. Disponible en web: http://www.luern.fr/Tropaion.pdf Consultado: 6 de diciembre de 2010.

Poux, M., Foucras, S. (2008): “Du banquet gaulois au sacrifice romain. Pratiques rituelles dans le sanctuaire de Corent, cité des Arvernes. » en Lepetz, S., Van Andringa, W. : Le sacrifice animal en Gaule romaine. Actes de la table-ronde de Paris (Muséum d'Histoire Naturelle), septembre 2002, pp. 163-184. Eds. Monique Mergoil, Montagnac.

Poux, M (Dir.), (2008) : Sur les traces de César. Militaria tardo-républicains en contexte gaulois. Actes de la Table Ronde de Glux-enGlenne, 17 octobre 2002. Bibracte.

Quesada Sanz, F. (2007) : Estandartes militares en el mundo antiguo. Aquila Legionis, 8. Madrid.

Rapin, A (1996) : «Les armes des celtes. Des messages enfouis sous la rouille. » Mélanges de l'Ecole française de Rome, Antiquité, vol. 108, 2. pp. 505-522.
Requi, C., Benquet, L. (2009) : « Les « dépôts » de la région toulousaine au second âge du Fer. » In Bonnardin, S., Hamon, C., Lauwers, M., Quilliec, B. (Dirs) : Du matériel au spiritul. Réalités archéologiques et historiques des " dépots» de la Préhistoire à nos jours. XXIXèmes rencontres internationales d'archéologie et d'histoire d'Antibes, pp. 429-435.

Roure, R., Girard, B. (2007) : « Le mobilier métallique du dépôt du Cailar : quantification, composition et traces de manipulations destructives » en Daubigney, A., Barral, Ph., Dunning, C., Kaenel, G., Roulière-Lambert, M.-J. (dirs.): L'âge du Fer dans l'arc jurassien et ses marges. Dépôts, lieux sacrés et territorialité à l'âge du Fer. Actes du XXIXème colloque de L'AFEAF, Bienne 5-8 Mai 2005. Presses universitaires de Franche-Comté.

Roure, R. (2009) : «Armes et têtes coupées au Cailar (Gard) : premiers éléments de réflexion sur un dépôt rituel en Gaule méditerranéenne. » en Honegger, M., Ramseyer, D., Kaenel, G., Arnold, B., Kaeser, M.-A. (dirs.) : Le site de La Tène : bilan des connaissances - état de la question. Actes de la Table ronde internationale de Neuchâtel, 1-3 novembre 2007. Archéologie Neuchâteloise 43, Neuchâtel, pp. 645-650.

V. V. A. A. (1992) : Les fouilles du Parking de la Mairie à Besançon. 20000 ans d'Histoire. Musée des Beaux-Arts et d'Archéologie de Besançon.

Verdin, F., Bardot, X (2007) : « Les puits de l'Ermitage (Agen, Lot-et-Garonne). » en IzacImbert, L. (Dir.), 2007, pp. 237-257.

Webster, J. (1996) : «Sanctuaries and sacred places » en Green, M. : The Celtic World. Routledge, London-New York. 